\title{
p53 Regulates the Neuronal Intrinsic and Extrinsic Responses Affecting the Recovery of Motor Function following Spinal Cord Injury
}

\author{
Elisa M. Floriddia, ${ }^{1,2}$ Khizr I. Rathore, ${ }^{1}$ Andrea Tedeschi, ${ }^{1,3}$ Giorgia Quadrato, ${ }^{1}$ Anja Wuttke, ${ }^{1}$ Jan-Matthis Lueckmann, ${ }^{1}$ \\ Kristina A. Kigerl, ${ }^{4}$ Phillip G. Popovich, ${ }^{4}$ and Simone Di Giovanni ${ }^{1}$ \\ ${ }^{1}$ Laboratory for NeuroRegeneration and Repair, Center for Neurology, Hertie Institute for Clinical Brain Research, University of Tübingen, and ${ }^{2} \mathrm{Graduate}$ \\ School for Cellular and Molecular Neuroscience, University of Tübingen, D-72076 Tübingen, Germany, ${ }^{3}$ Axonal Growth and Regeneration Laboratory, \\ German Center for Neurodegenerative Disease, D-53175 Bonn, Germany, and ${ }^{4}$ Center for Brain and Spinal Cord Repair, The Ohio State University, \\ Columbus, Ohio 43210
}

Following spinal trauma, the limited physiological axonal sprouting that contributes to partial recovery of function is dependent upon the intrinsic properties of neurons as well as the inhibitory glial environment. The transcription factor p53 is involved in DNA repair, cell cycle, cell survival, and axonal outgrowth, suggesting p53 as key modifier of axonal and glial responses influencing functional recovery following spinal injury. Indeed, in a spinal cord dorsal hemisection injury model, we observed a significant impairment in locomotor recovery in $\mathrm{p} 53^{-1-}$ versus wild-type mice. $\mathrm{p} 53^{-1-}$ spinal cords showed an increased number of activated microglia/macrophages and a larger scar at the lesion site. Loss- and gain-of-function experiments suggested p53 as a direct regulator of microglia/macrophages proliferation. At the axonal level, $\mathrm{p} 53^{-l-}$ mice showed a more pronounced dieback of the corticospinal tract (CST) and a decreased sprouting capacity of both CST and spinal serotoninergic fibers. In vivo expression of p53 in the sensorimotor cortex rescued and enhanced the sprouting potential of the CST in $\mathrm{p} 53^{-I-}$ mice, while, similarly, p53 expression in p53 $3^{-1-}$ cultured cortical neurons rescued a defect in neurite outgrowth, suggesting a direct role for $\mathrm{p} 53$ in regulating the intrinsic sprouting ability of CNS neurons. In conclusion, we show that p53 plays an important regulatory role at both extrinsic and intrinsic levels affecting the recovery of motor function following spinal cord injury. Therefore, we propose p53 as a novel potential multilevel therapeutic target for spinal cord injury.

\section{Introduction}

Following spinal cord trauma, there is a very limited potential for axonal sprouting and regeneration as well as related functional recovery due to the formation of a spinal glial inhibitory environment and to deficient intrinsic pro-regenerative properties of neurons (Yiu and He, 2006; Giger et al., 2008; Di Giovanni, 2009; Liu et al., 2011). However, in the case of incomplete lesions of the spinal cord, some physiological axonal sprouting and plasticity that contribute to partial recovery of motor function does occur (Raineteau and Schwab, 2001; Raineteau et al., 2002; Bareyre et al., 2004). The identification of factors that play a role in both the neuronal intrinsic and extrinsic spinal environment after lesion may affect the proaxonal regenerative response and functional

\footnotetext{
Received April 20, 2012; revised July 5, 2012; accepted Aug. 10, 2012.

Author contributions: E.M.F., A.T., and S.D.G. designed research; E.M.F., K.I.I., A.T., G.Q., A.W., J.-M.L., and K.A.K. performed research; E.M.F., K.I.R., and S.D.G. analyzed data; E.M.F., K.I.R., P.G.P., and S.D.G. wrote the paper.

This work was supported by The Hertie Foundation, Deutsche Forschungsgemeinschaft Grants DI 1497/1-1 and DI 1497/3-1, and Wings for Life (S.D.G.). We thank Uli Nauman for the production of the p53 adenovirus; Roberta Brambilla, Lisa Schnell, and Miriam Gullo for invaluable scientific and technical support; and Samuel David for the comments on this manuscript.

Correspondence should be addressed to Dr. Simone Di Giovanni, Laboratory for NeuroRegeneration and Repair, Hertie Institute for Clinical and Brain Research, University of Tübingen, Otfried-Mueller Strasse 27, D-72076 Tübingen, Germany. E-mail: simone.digiovanni@medizin.uni-tuebingen.de.

DOI:10.1523/JNEUROSCI.1925-12.2012

Copyright $\odot 2012$ the authors $\quad 0270-6474 / 12 / 3213956-15 \$ 15.00 / 0$
}

recovery. Recently, we have shown that the transcription factor p53 is required for axonal regeneration of the injured facial nerve and for neurite outgrowth of cultured cortical and dorsal root ganglia neurons (Di Giovanni et al., 2006; Tedeschi et al., 2009a,b; Floriddia et al., 2011).

In mitotic cells and in cancer, p53 has been shown (1) to negatively regulate cell proliferation through the transcriptional regulation of cell cycle arrest genes, such as p21 (Liebermann et al., 2007; Abbas and Dutta, 2009), and (2) to mediate cell death in highly damaged cells following a variety of stressors, including oxidative stress, DNA damage, and growth factor deprivation (Aloyz et al., 1998; Sakaguchi et al., 1998; Culmsee and Mattson, 2005).

Previous reports have suggested that p53 (Saito et al., 2000) and p53-dependent signaling (Carmel et al., 2001; Di Giovanni et al., 2003; Byrnes et al., 2006) are activated in both neuronal and glial cells following spinal cord injury (SCI). In addition, we previously found that p53-dependent target genes, including DNA damage, cell cycle, and axonal plasticityrelated molecules are triggered mainly between 1 and $7 \mathrm{~d}$ following injury (Di Giovanni et al., 2005a,b). Thus, we hypothesize that p53 may be important for the regulation of axonal sprouting in the injured spinal cord, for physiological recovery of locomotion, as well as for the establishment of the postinjury glial environment. 
Table 1. Antibodies

\begin{tabular}{llll}
\hline Primary antibody & Supplier & Catalog \# & Application \\
\hline 5-HT & ImmunoStar & 20080 & Rabbit \\
Caspase-3 (H-277) & Santa Cruz & sc-7148 & Rabbit \\
Caspase-3 (cleaved) & Cell Signaling & 9661 & Rabbit \\
CD11b & AbD Serotec & MCA711 & Rat \\
CD16/32 & BD Biosciences Pharmingen & 553142 & Rat \\
CD206 & R\&D Systems & AF2535 & Goat \\
Fibronectin & Sigma-Aldrich & F3648 & Rabbit \\
GAPDH & Millipore & MAB374 & Mouse \\
GFAP & Invitrogen & $13-0300$ & Rat \\
GFAP & Millipore & AB5804 & Rabbit \\
Iba1 & Wako Chemicals & $019-19741$ & Rabbit \\
Ki67 & BD Biosciences Pharmingen & $1: 800$ IHC & Mouse \\
P53(CM5) & Leica & 1:100 IHC & 1:500 IHC \\
PCNA & Merck & NCL-p53-CM5p & Rabbit \\
\hline
\end{tabular}

Table 2. Primers

\begin{tabular}{lll}
\hline Gene & Primer forward & Primer reverse \\
\hline Collagen $1 \alpha 2$ & GTAAACACCCCAGCGAAGAACTC & TCAAACTGGCTGCCACCAT \\
Collagen $4 \alpha 1$ & TTCAGATTCCGCAGTGCCCTA & TTCTCATGCACACTTGGCAGC \\
Fibronectin & ACAGAAATGACCATTGAAGG & TGTCTGGAGAAAGGTTGATT \\
GADD45 $\alpha$ & CAGGGGAGGGACTCGCACTT & CGGGGTCTACGTGAGCAGC \\
GAP-43 & CAGGAAAGATCCCAAGTCCA & GAACGGAACATTGCACACAC \\
GAPDH & GCTTAAGAGACAGCCGCATCT & CGACCTTCACCATTTGTCTACA \\
p21 & CGGTGGAACTTGACTTGG & AGAGTGCAAGACAGCGACAA \\
p53 & AGAGACCGCGGACAGAAGA & CTGTAGCATGGGCATCCTTT \\
\hline
\end{tabular}

To this end, we performed a T10 bilateral dorsal hemisection of the spinal cord in wild-type (wt) and $\mathrm{p}^{-1-}$ mice. Strikingly, we found that physiological recovery of motor function was impaired in $\mathrm{p} 53^{-1-}$ mice, which showed a more pronounced dieback of the corticospinal tracts (CST) as well as a clear impairment of serotoninergic (5-HT) and CST sprouting. In addition, $\mathrm{p} 53^{-/-}$mice displayed a larger fibrotic scar and an increased number of activated microglia/macrophages at the lesion site, due to aberrant proliferation. Moreover, the impairment in CST sprouting in $\mathrm{p} 53^{-1-}$ mice could be rescued by $\mathrm{p} 53$ gain of function, supporting a direct role for p53 in the modulation of the intrinsic neuronal response of the CST.

Together, these data suggest that p53 affects the natural neuronal and glial adaptive response to spinal injury that leads to partial spontaneous recovery of motor function.

\section{Materials and Methods}

Mice

Mice were purchased from The Jackson Laboratory. Wild-type and p53 ${ }^{-1-}$, B6.129S2-Trp53 ${ }^{\text {tm1Tyj/J }}$ (Jacks et al., 1994) mice used in this study were male and strain matched. The age of the mice used for experiments was 8 weeks. p53 ${ }^{-1-}$ mice did not show any visible phenotype. We did not observe any behavioral or learning difference compared with wild type during the training for the behavioral assessments.

\section{Surgical procedure and postoperative care}

Mice were kept under anesthesia with $2 \%$ isoflurane $/ 1 \% \mathrm{O}_{2}$ mixture. Body temperature was maintained by keeping the mice on a heating pad $\left(37^{\circ} \mathrm{C}\right)$ during the whole procedure. The skin over the thoracic area was shaved and cleaned three times with Softasep N (Braun). The skin was incised, the superficial fat shifted apart, and the muscle tissue dissected to expose laminae T9-T11. A T10 laminectomy was performed, the dura mater was removed, taking care not to damage the spinal cord during this procedure. A dorsal hemisection until the central canal was performed with a microknife (FST). To ensure that the lesion was complete, the microknife was passed throughout the dorsal part of the spinal cord several times. This kind of injury damages the dorsal and lateral CST, the dorsal columns, the rubrospinal, the dorsal and lateral raphe-spinal, and part of the reticulospinal tracts. For the laminectomy control surgery, the dura mater was removed, but the dorsal hemisection was not performed. After surgery, mice were placed back in their cages warmed up with an infrared light to prevent hypothermia. Mice underwent daily check for general health, mobility within the cage, wounds, swelling, infections, or autophagy of the toes throughout the experiment. The animals showed neither skin lesions nor autophagy throughout the study. Mice were injected subcutaneously with $1 \mathrm{ml}$ of $0.9 \%$ saline twice daily for $3 \mathrm{~d}$ and once daily from days 4 to 7 after surgery. Bladders were manually expressed twice daily for the first week after operation and once daily until needed.

\section{Tracer and virus injections}

To trace the CST, biotinylated dextran amine (BDA) mini-ruby (10\% in 0.01 M PBS; 10,000 MW; Invitrogen) injection was performed in the right sensorimotor cortex (SMC) $14 \mathrm{~d}$ before killing. To infect layer $\mathrm{V}$ neurons, Adeno-GFP or Adeno-GFP-p53 dual promoter viral constructs $(5.3 \times$ $10^{7} \mathrm{pfu}$ ) were injected through a glass capillary connected with a $5 \mu \mathrm{l}$ Hamilton syringe in the right sensorimotor cortex on the day of the spinal injury. Mice were anesthetized, and the head was shaved and cleaned as above. Mice were placed on a stereotaxic device, the scalp was incised, and a craniotomy on the right sensorimotor cortex was performed with a drill. The viruses or the tracer were injected in a total of four sites $(0.4 \mu \mathrm{l}$ per site over a period of 3-5 min, plus $3 \mathrm{~min}$ of the glass capillary in place to avoid spillover), coordinates were $1.0 \mathrm{~mm}$ lateral, 0.5 $\mathrm{mm}$ deep, and $+0.5,-0.2,-0.7$, and $-1 \mathrm{~mm}$ with respect to bregma (Steward et al., 2008).

\section{Tissue preparation and sectioning}

At the end of the survival period, the animals were deeply anesthetized with ketamine $(120 \mathrm{mg} / \mathrm{kg}$ body weight $)$ and xylazine $(14 \mathrm{mg} / \mathrm{kg}$ body weight) and perfused transcardially with $0.1 \mathrm{M}$ PBS, pH 7.4, and $4 \%$ PFA in PBS, pH 7.4. Dissected brains and spinal cords were further postfixed in $4 \%$ PFA in PBS at $4^{\circ} \mathrm{C}$ overnight and cryoprotected in $30 \%$ sucrose for at least $48 \mathrm{~h}$. After embedding in Tissue-Tek OCT compound, sagittal or coronal spinal cord and coronal brain sections were cut to a thickness of $20 \mu \mathrm{m}$. Sections were stored at $-20^{\circ} \mathrm{C}$ until further use.

\section{Behavioral assessments}

Training. All animals received training before surgery. The animals were gently handled and then acclimated to the open field for the locomotor test once daily for 10 sessions. They were also trained on the grid walk and CatWalk runaway once daily for seven sessions; each animal repeated three to four runs per session for each apparatus. For acclimation in the plantar heat test, each animal was allowed to remain in an acrylic box $(11.5 \times 11.5 \times 14 \mathrm{~cm})$ on a glass floor for 10 min daily for four sessions.

Open-field test. The Basso Mouse Scale (BMS) (Basso et al., 2006) was used to assess open-field locomotion for all injury group. Each animal 
was allowed to freely move in the open field for 4 min while two independent investigators blinded to the genotype scored it. The BMS score and subscore were given. Mice were tested before the surgery and 1, 3, 7, 14,21 , and $28 \mathrm{~d}$ following injury. Only the animals that showed frequent or consistent plantar stepping in the open field (BMS score $\geq 5$ ) were tested on the grid walk, CatWalk, and heat plantar test.

Grid walk. The grid walk test was used to evaluate the sensorimotor coordination of the hindlimbs (Behrmann et al., 1992; Ma et al., 2001). The animals were allowed to cross a $50 \mathrm{~cm}$ metal grid of $1.2 \times 1.2 \mathrm{~cm}$ grid spaces for three times for each testing day. The number of missteps was counted for each run. A misstep occurs when the animal cannot find or properly position his paw on the grid and his foot slips through the grid. Mice were tested before surgery and 14, 17, 21, 23, and $28 \mathrm{~d}$ following the injury.

CatWalk automated quantitative gait analysis test. The CatWalk test was used to evaluate basal motor behavior and coordination during continuous locomotion along a walkway (Hamers et al., 2001). The CatWalk apparatus and CatWalk XT 8.1 software (Noldus) were used. Each animal was allowed to cross the runway, $8 \times 50 \mathrm{~cm}$ wide with a glass floor, in a darkened room. The green LED light internally reflected in the glass floor illuminates the animal's paws at the contact area only, producing a footprint. The CatWalk apparatus also presents an illuminated ceiling with a red LED light that makes the body contour of the animal visible. On the experimental day, three runs for each animal were recorded from below the glass by a digital video camera [50 (PAL) fields per second]. The runs were then analyzed to measure the average speed, the step length, and the stand time parameters. Animals were tested before surgery and 14, 21, and $28 \mathrm{~d}$ following injury.

Plantar heat test. This test was used to measure basal sensitivity to noxious thermal stimulation. Thermal sensitivity of the plantar hindpaws was tested according to Hargreaeves' method (Hargreaves et al., 1988; Mogil et al., 1999), with a plantar test device (Ugo Basile).

On the experimental days, the animals were handled and placed unrestrained in an acrylic box for 10-15 min to acclimate before testing. An infrared radial source $(26 \mathrm{~W}$ ) was applied through a glass floor to the middle of the plantar surface of the hindpaw, between the footpads, when the animal was stationary. Each mouse was tested for five times for each hindpaw, with at least $30 \mathrm{~s}$ between trials, in a randomized order of testing to minimize avoidance behavior. A $30 \mathrm{~s}$ cutoff was set to avoid tissue damage. The time of withdrawals and any other behavior indicating a supraspinal response, such as licking, looking at the affected paw, or attacking the stimulus, were recorded. Highest and lowest latencies for each paw were dropped, and the remaining six latencies for each mouse were averaged. Animals were tested before surgery, at 22 , and $29 \mathrm{~d}$ following injury.

\section{Histology}

Antibody control experiments. Control experiments for antibody specificity were performed using secondary antibody alone for each staining performed. For the rabbit anti-p53 (CM5; Leica) antibody, spinal cord and brain sections from $\mathrm{p} 53^{-1-}$ mice were also stained. No specific staining was seen in any condition. Full details of the primary antibodies used are reported in Table 1.

Immunofluorescent staining. Sections of wt and $\mathrm{p} 53^{-1-}$ spinal cords were blocked with $10 \%$ bovine serum albumin (BSA) in TBS for $1 \mathrm{~h}$ at room temperature and then incubated with rat anti-GFAP (Invitrogen) or rabbit anti-fibronectin (Sigma-Aldrich) antibodies in 2\% BSA, 0.2\% TBS-Triton at $4^{\circ} \mathrm{C}$ overnight. This was followed by incubation with Alexa Flour 488-conjugated goat anti-rat or anti-rabbit antibodies at room temperature for $1 \mathrm{~h}$. Counterstaining was performed with DAPI (1: 10,000) (Invitrogen) in PBS, and sections were coverslipped.

Immunofluorescent double staining. Spinal cord sections from wt and $\mathrm{p}^{-1-}$ mice were blocked with $10 \%$ BSA in TBS at room temperature for $1 \mathrm{~h}$ and then incubated with rat anti-GFAP (Invitrogen) in $2 \%$ BSA, $0.2 \%$ TBS-Triton or rat anti-CD11b (AbD Serotec) in $2 \%$ BSA in TBS antibodies at $4^{\circ} \mathrm{C}$, overnight. This was followed by incubation with rabbit anti-rat biotinylated antibody (1:200) (Vector Laboratories) in 2\% BSA in TBS at room temperature for $1 \mathrm{~h}$ and protection with Alexa Fluor 488-conjugated streptavidin (1:500) (Invitrogen) in $2 \%$ BSA in TBS at room temperature for $1 \mathrm{~h}$. Antigen retrieval with $0.1 \mathrm{M}$ citrate buffer, $\mathrm{pH} 6.2$, at $98^{\circ} \mathrm{C}$ for $20 \mathrm{~min}$ was performed, followed by blocking in 10\% BSA in $0.2 \%$ TBS-Triton for $1 \mathrm{~h}$ at room temperature and incubation with mouse anti-Ki67 (BD Biosciences Pharmingen) or rabbit anti-p53 (CM5; Novacastra) antibodies in $2 \% \mathrm{BSA}$ in $0.2 \%$ TBS-Triton at $4^{\circ} \mathrm{C}$, overnight. Then the sections were incubated with Alexa Fluor 568-conjugated goat antimouse or anti-rabbit antibodies (1:1500) in 2\% BSA in TBS for $1 \mathrm{~h}$ at room temperature. Counterstaining was performed with DAPI (1: 10,000) (Invitrogen) in PBS, and sections were coverslipped. For p53 immunostaining, the antigen retrieval with $0.1 \mathrm{M}$ citrate buffer, $\mathrm{pH}$ 6.2 , was followed by proteinase $\mathrm{K}$ treatment at $37^{\circ} \mathrm{C}$ for $15 \mathrm{~min}$.

Immunofluorescent staining for CD16/32, CD206, and Iba1. Spinal cord sections from wt and $\mathrm{p} 53^{-1-}$ mice were blocked in $4 \%$ BSA, $0.1 \%$ TBSTriton X-100 for $1 \mathrm{~h}$ at room temperature, and then incubated with rat anti-CD16/32 (BD Biosciences Pharmingen), goat anti-CD206 (R\&D Systems), or rabbit anti-Ibal (Wako Chemicals) in 2\% BSA, 0.1\% TBSTriton X-100 overnight at room temperature. This was followed by sequential incubation with Alexa Fluor 546-conjugated donkey anti-goat or anti-rat or Alexa Fluor 488-conjugated goat anti-rabbit (1:1000) (Invitrogen) for $1 \mathrm{~h}$ at room temperature. Slides were counterstained with DAPI (1:10,000) for $15 \mathrm{~min}$ and coverslipped.

$D A B$ immunostaining. Spinal cord or brain sections from wt and $\mathrm{p} 53^{-1-}$ mice were used. Antigen retrieval with $0.1 \mathrm{M}$ citrate buffer, $\mathrm{pH}$ 6.2 , at $98^{\circ} \mathrm{C}$ for $20 \mathrm{~min}$, followed by proteinase $\mathrm{K}$ treatment at $37^{\circ} \mathrm{C}$ for 15 min were performed in case of $\mathrm{p} 53$ staining. The peroxidase activity was blocked in $0.3 \% \mathrm{H}_{2} \mathrm{O}_{2}$ in TBS for $15 \mathrm{~min}$ at room temperature, the sections were incubated in 10\% BSA in TBS for $1 \mathrm{~h}$ at room temperature and then with rabbit anti-p53 (CM5; Leica) antibody in 2\% BSA $0.3 \%$ TBS-Triton or rat anti-CD11b antibody (AbD Serotec) in 2\% BSA TBS at $4^{\circ} \mathrm{C}$ overnight. This was followed by incubation in biotinylated goat anti-rabbit or rabbit anti-rat secondary antibodies (1:200) (Vector Laboratories) in $2 \%$ BSA TBS for $1 \mathrm{~h}$ at room temperature, followed by incubation in $\mathrm{ABC}$ complex for $90 \mathrm{~min}$ at room temperature. Staining was revealed with $\mathrm{DAB}$. Counterstaining was performed with hematoxylin/eosin. Sections were dehydrated and coverslipped.

5-HT immunostaining. We followed a protocol for the detection of the serotoninergic fibers optimized by Müllner et al. (2008). In brief, following a second postfixation of the sections on slide (4\% paraformaldehyde, $0.1 \%$ glutaraldehyde), antigen retrieval in citrate buffer $(0.1 \mathrm{~m}), \mathrm{pH} 4.5$, by microwave irradiation was performed. The sections were incubated with rabbit anti-5-HT (4\% normal goat serum in 0.3\% TBS-TX; ImmunoStar) antibody for $4 \mathrm{~d}$ at $4^{\circ} \mathrm{C}$, followed by $\mathrm{ABC}$ complex and secondary biotinylated goat anti-rabbit antibody $(1: 300 ; 2 \%$ normal goat serum in $0.3 \%$ TBS-TX) incubations. Then, the signal was further amplified with biotinylated tyramide [ $50 \mathrm{~mm}$ borate buffer, $\mathrm{pH}$ 8.0, 0.25\% biotin (long arm) NHS; Vector Laboratories]. The signal was detected by incubation in diaminobenzidine tetrahydrochloride (DAB) (Vector Laboratories), and the slides were dehydrated and coverslipped.

Reverse transcriptase qPCR. The lesion sites of the spinal cords from wt and $\mathrm{p} 53^{-1-}$ mice were collected separately and snap frozen in liquid nitrogen. The frozen tissues were ground with a pestle to a fine powder. Total RNA was extracted with the High Pure RNA Paraffin kit (Roche). After RNA quantification, $1 \mu \mathrm{g}$ of total RNA for each sample was retro-transcribed into cDNA with the SuperScript II Reverse Transcriptase system (Invitrogen). The cDNA obtained from this reaction was diluted 1:5, and $1 \mu \mathrm{l}$ of the diluted cDNA was used as template for each qPCR. Primers for p53, p21, GAP-43, GADD45, Fibronectin, Collagen $1 \alpha 2$ and $4 \alpha 1$, and GAPDH were used (primer sequences are reported in Table 2). qPCRs were run in triplicates using SYBR Green probe (Thermo Fisher Scientific) and an ABI Prism 7500 system (Applied Biosystems). Melting curve analysis was performed for each reaction to ensure single amplified products. Expression of the genes of interest following the injury was calculated with the $\Delta \Delta$ Cts analysis, normalizing to GAPDH and to the expression of the genes of interest in laminectomy control operation for each gene.

Western blotting. The lesion sites of the spinal cords from wt and p $53^{-1-}$ mice were collected separately in RIPA buffer supplemented with protease inhibitors mixture (Roche) and sonicated. Protein concentration was then determined by BCA assay kit (Pierce). Protein extracts were subjected to SDS-PAGE and blotted onto nitrocellulose membrane (Invitrogen). Membranes were blocked with $8 \%$ skimmed milk or $5 \%$ 


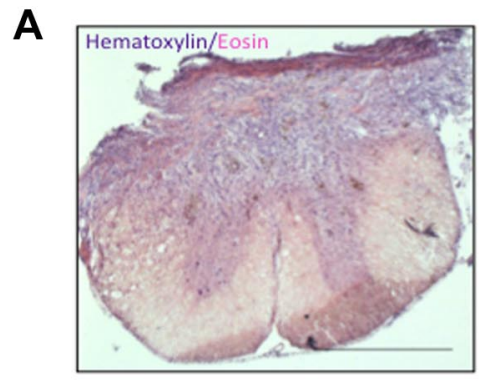

C

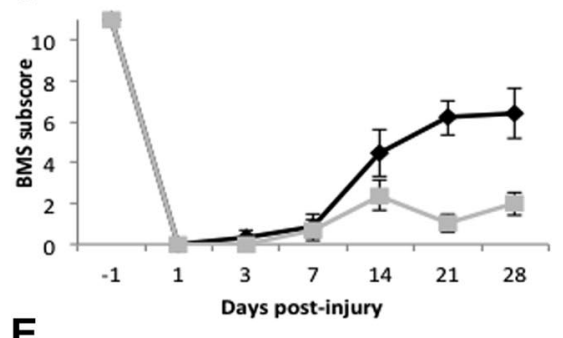

E

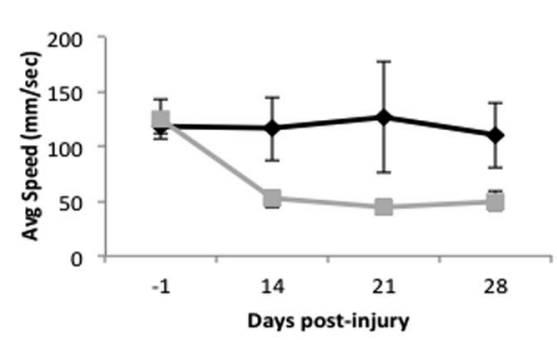

G

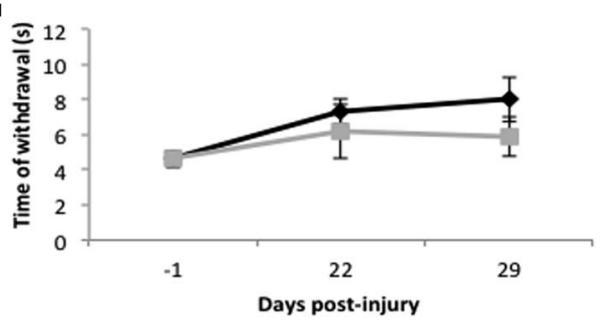

Figure 1. $p 53$ is required for the recovery of motor function following spinal cord injury. $A$, Representative microphotograph of hematoxylin/eosin staining showing the morphology of the lesion, which reaches beyond the central canal after a T10 bilateral dorsal hemisection. Shown is a coronal spinal cord section at $28 \mathrm{~d}$ postoperation (dpo). Scale bar, $500 \mu \mathrm{m} . \boldsymbol{B}, \boldsymbol{C}$, In the open field,

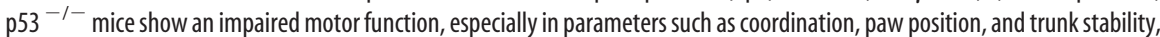
as shown by the BMS subscore (C). Repeated-measurements ANOVA, $p \leq 0.01$. D, In the grid walk, $\mathrm{p} 53^{-1-}$ mice perform a greater number of missteps compared with wt mice following spinal cord injury at all time points tested. Repeated-measurements ANOVA, $p \leq 0.01 . \boldsymbol{E}, \boldsymbol{F}$, In the automated CatWalk gait analysis, $\mathrm{p5} 3^{-1-}$ mice walk slower $(\boldsymbol{E})$ and perform shorter steps $(\boldsymbol{F})$ at all time points tested. Repeated-measurements ANOVA, $p \leq 0.01(\boldsymbol{E})$, and $p \leq 0.05(\boldsymbol{F})$. G, In the Hargraeves' heat plantar test, the time of withdrawal from the heating source was comparable between genotypes. No differences between genotypes before injury were observed. Before surgery, 10 animals for each genotype were tested in each task. Following the injury, 10 animals for each genotype were tested in the open field and when the animals show frequent or consistent plantar stepping (BMS score $\geq 5$ ) were tested in the other tasks ( $n=6-10$ for each genotype). During test, scoring was performed by two investigators blinded to the genotype. All measures are averages \pm SEM.

BSA in $0.1 \%$ TBS-T, accordingly to the first antibody used. Incubation with rabbit anti-GFAP (Millipore) in 5\% skimmed milk TBS, rabbit anti-caspase-3 (Santa Cruz) in 2\% BSA, 0.1\% TBS-T, mouse antiproliferating cell nuclear antigen (PCNA) (Merck) in 3\% BSA in $0.1 \%$ TBS-T, mouse anti-GAPDH (Millipore) in 3\% skimmed milk TBS antibodies was performed at $4^{\circ} \mathrm{C}$ overnight. This was followed by incubation with HRP-conjugated anti-rabbit or anti-mouse antibodies (Thermo Fisher Scientific) at room temperature for $1 \mathrm{~h}$. Protein bands were visualized on film (GE Healthcare) using ECL-detecting reagents (Pierce). Full details of the primary antibodies used are reported in Table 1.

\section{Anatomical analysis}

All anatomical analyses were performed in a blinded fashion.

Quantification of the lesion core and reactive astrocytic areas. The area of the digitally acquired images was determined with the measure outline option of the AxioVision software (Zeiss). Three to five sagittal sections for each spinal cord for each animal were analyzed. Sections were serially chosen $(1: 12)$ in the medial part of the spinal cord, where the lesion tends to be more consistent. The lesion core and the reactive astrocytes area were identified as fibronectin-, GFAP-immunopositive areas, respectively. GFAP-negative tissue was defined as tissue that shows absent or little GFAP immunoreactivity with only sparse GFAP-positive cells or processes (Camand et al., 2004; Park et al., 2005).

Stereological analysis of activated microglial macrophages. Ten to 11 sagittal sections for each spinal cord for each animal were analyzed. Sections were serially chosen (1:8), and the StereoInvestigator 7 (MBF Bioscience) software was used to stereologically estimate the number of CD11 ${ }^{+}$cells with the optical fractionator probe. Cells were counted within the lesion site in an unbiased fashion by a blinded investigator. Inclusion criteria to determine activated macrophage/microglia cells were the CD11b immunoreactivity and the round shape.

Quantification of proliferating astrocytes and microglia/macrophages. Five to six sagittal sections for each spinal cord for each animal were analyzed. Sections were serially chosen (1:8) as representative of the most ventral part of the lesion for consistency reasons. Photomicrographs in $z$-stack were acquired with the AxioVision software (Zeiss) through the Imager.Z1 microscope equipped with Apotome (Zeiss). GFAP or CD11b positive and double positive for Ki67 cells were counted within the reactive astrocytic area at the lesion site.

Analysis of M1/M2 macrophage populations. To determine the percentage of Iba ${ }^{+}$macrophages that were expressing CD16/32 or CD206, fluorescent images were collected at $20 \times$ on a Zeiss AxioScope2 equipped with Apotome. Two images were collected per section (from five to six sections per animal) from regions just rostral and caudal to the injury center. Total target areas of Iba1, CD206, and CD16/32 staining were quantified for each image using the MCID Elite image analysis software (InterFocus Imaging). Target area for CD206 and CD16/32 was normalized to Ibal target area for each image to calculate the proportion of double-labeled cells.

Densitometry analysis of 5-HT immunoreactivity. Bright-field pictures were taken from four to six random sections for each distance $(2 \mathrm{~mm}$ rostral, 1,3 , and $5 \mathrm{~mm}$ caudal to the injury site) from each spinal cord for each animal at constant illumination intensity (Faden et al., 1988; Saruhashi et al., 1996; Oatway et al., 2005). For laminae VII-IX, care was taken to exclude any fibers from the intermediolateral nucleus (IML) to avoid redundant quantification. The digitalized images were converted in grayscale format ( $8 \mathrm{bit}$ ), and the densitometry analysis was performed with the software ImageJ (NIH). The area measured was held constant and the background level was determined from an area of the ventral funiculus that did not exhibit immunoreactivity. This background level was used to set the threshold between labeled and background pixels. 
A

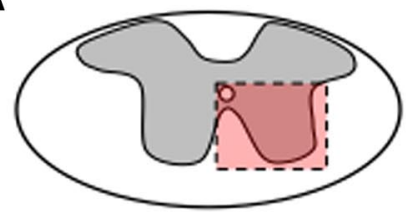

B
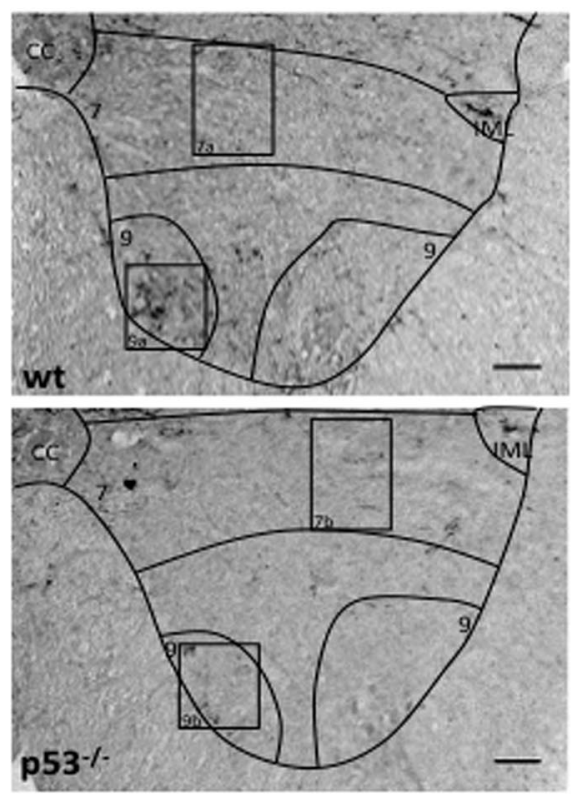
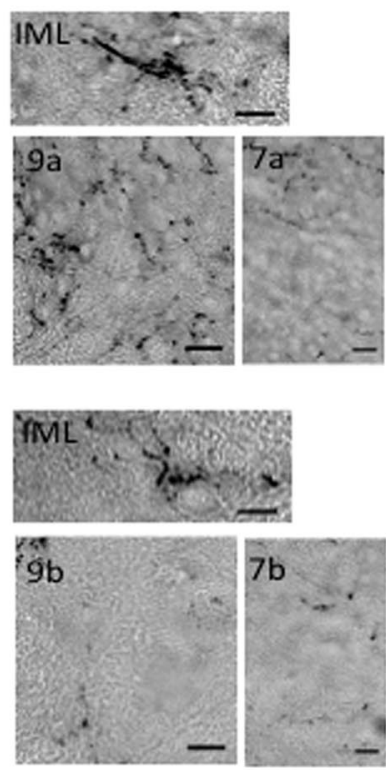

C

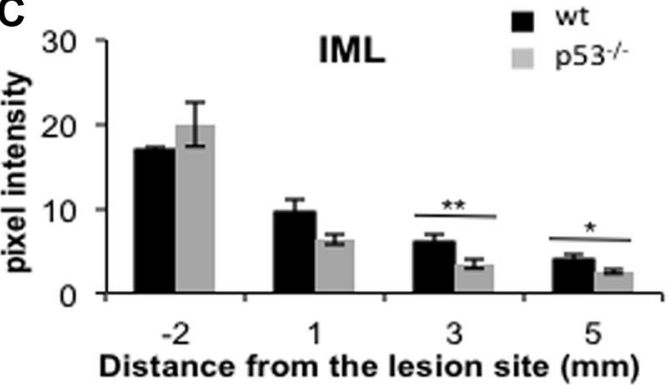

D

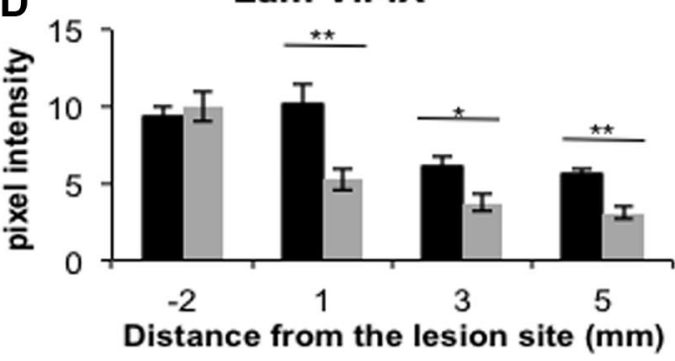

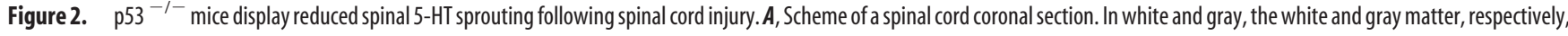
with the central canal in the middle of the gray matter. The red square highlights the analyzed region of interest. $\boldsymbol{B}-\boldsymbol{D}$, Representative pictures $(\boldsymbol{B})$ and quantification $(\boldsymbol{C}, \boldsymbol{D})$ of 5 -HT immunopositive fibers in laminae VII and IX and IML in wt and $\mathrm{p} 53^{-1-}$ mice following spinal cord injury. Pixel intensity quantification of density and distribution of 5 -HT fibers show reduced sprouting in $\mathrm{p} 53^{-/-}$ compared with wt mice below, but not above the injury site $(\boldsymbol{C}, \boldsymbol{D})\left(n=6 \mathrm{wt}\right.$ and $7 \mathrm{p} 53^{-1-}$ mice). In $\boldsymbol{B}$, cc, Central canal; 7 and 9 , laminae 7 and 9 ; IML, intromediolateral cell column. Scale bar: $\boldsymbol{B}$, Lower magnification, $50 \mu \mathrm{m}$; higher magnification, $20 \mu \mathrm{m}$. All tissues were collected at $28 \mathrm{dpo}$. All measures are averages \pm SEM. Student's $t$ test, ${ }^{*} p \leq 0.05,{ }^{* *} p \leq 0.01$.

Quantification of CST dieback, sprouting, and end bulbs. For each animal, four to six consecutive sagittal sections from the most ventral part of the spinal cord using the central canal as landmark were chosen and analyzed with the software AxioVision (Zeiss) to measure the CST dieback or StereoInvestigator 7 (MBF Bioscience) to count axons, sprouts, and end bulbs.

Dieback of the dorsomedial CST was measured as the distance between the axon bundle and the border of the lesion site identified by GFAP immunoreactivity (Shen et al., 2009). The quantification of the sprouting and end-bulb indexes of the dorsomedial CST was performed proximal to the lesion site at rostral and caudal level. For each section, the BDA-labeled sprouts, end bulbs, and axons were counted live. The sum of the total number of labeled sprouts or bulbs was normalized to the total number of labeled axons above the lesion site counted in all the analyzed sections for each animal, obtaining an interanimal comparable ratio considering the individual tracing variability (Schnell and Schwab, 1993; Simonen et al., 2003). Sprouts and regrowing fibers were defined following the anatomical criteria reported by Steward et al. (2003). Briefly, we considered as a sprout or a regrowing axon fibers that originate at or near an amputation site, take unusual paths through the tissue environment, are tipped with growth cones, or present unusual morphology (e.g., unusual branching pattern).

\section{Primary microglia cultures}

Purified microglia was prepared from neonatal $\mathrm{P} 1-\mathrm{P} 3$ wt and $\mathrm{p} 53^{-1-}$ mice as described previously (Saura et al., 2003). Briefly, cortices were dissected out, the meninges were carefully removed, and the tissue was minced with microscissors. After incubation with $0.125 \%$ trypsin EDTA/ HBSS for $10-15 \mathrm{~min}$ at $37^{\circ} \mathrm{C}$, a single-cell suspension was obtained by trituration through a fire-polished glass pipette. The suspension was fil- tered through a $40 \mu \mathrm{m}$ filter to remove debris. After a subsequent wash, cells were plated in $25 \mathrm{~cm}^{2}$ tissue culture flasks at 62,500 cells per $\mathrm{cm}^{2}$. Cultures were incubated in standard cell culture conditions until confluency. At this stage, flasks were maintained for an additional 2 weeks. Cultures maintained for $\sim 20-25$ DIV were incubated with 0.25\% trypsin in DMEM/F-12 (1:4) until the top layer of cells has detached. The remaining microglia were detached with undiluted trypsin and vigorous pipetting. These cells were used for all subsequent assays and were typically $>95 \%$ microglia as assessed by CD11b staining.

\section{Proliferation assay}

In vitro cell proliferation was assessed in microglia cultures by using a fluorometric BrdU cell proliferation assay (Calbiochem). The assay was performed per the manufacturer's protocol. Briefly, freshly purified cells were plated at 8000 cells/well in a 96-well plate. BrdU was added to the cell culture medium (10\% FBS/DMEM) for a period of $48 \mathrm{~h}$, at the end of which the plate was processed to read in a fluorescence plate reader.

\section{Proliferation assay with adenovirus infection}

For these experiments, freshly isolated cells were plated at 5000 cells per well in 96-well plates and incubated in standard cell culture conditions for $24 \mathrm{~h}$. Cells were then infected with Adeno-GFP virus or Adeno-p53 virus at 100 MOI. A no-virus control was also included. After an additional $24 \mathrm{~h}$, BrdU was added to the cell culture medium for $24 \mathrm{~h}$, and the plate was processed at the end of this $24 \mathrm{~h}$ period.

\section{Cell survival}

In vitro cell death was assessed using the Annexin V-FITC apoptosis detection kit (Calbiochem) per the manufacturer's protocol. Briefly, 


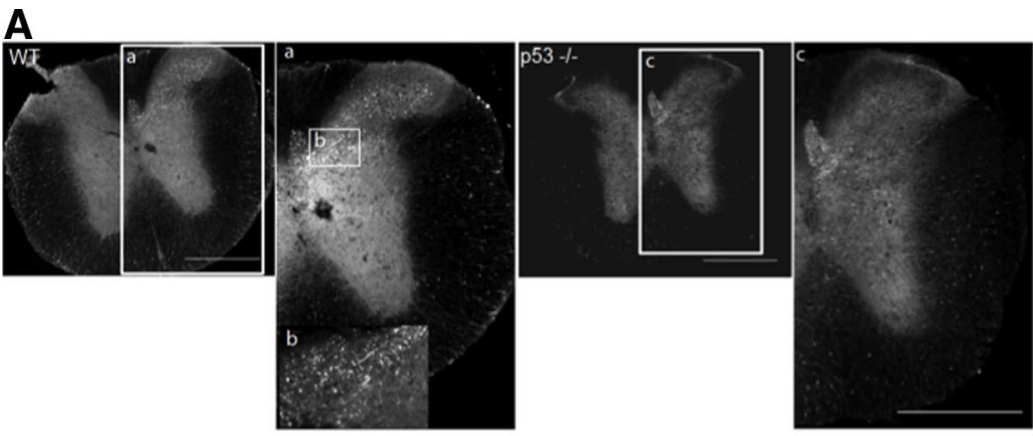

B
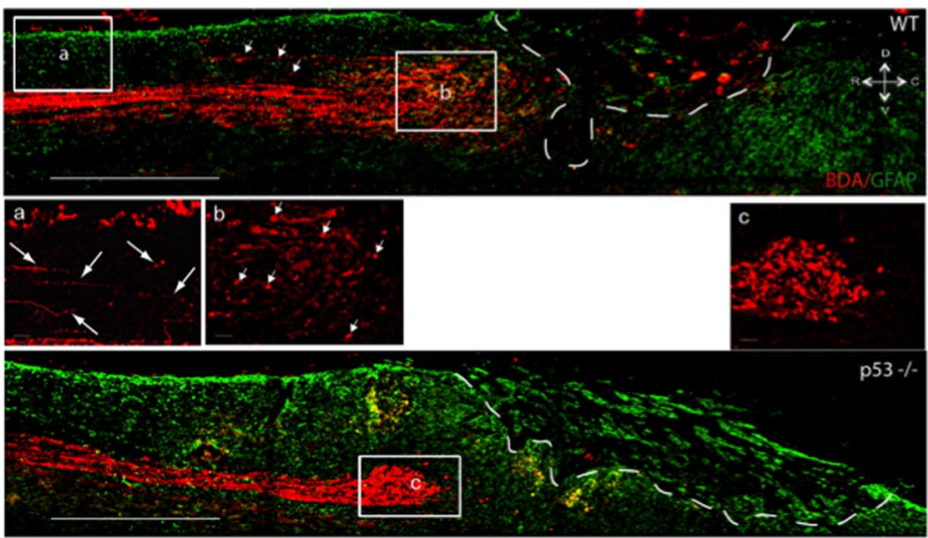

\section{C}

D
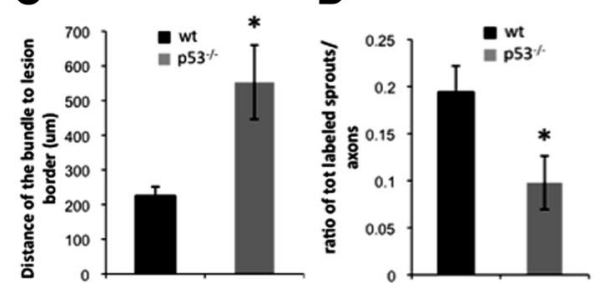

\section{E}

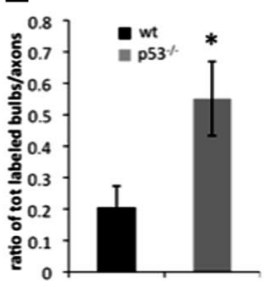

Figure 3. $\mathrm{p} 53^{-1-}$ mice show impaired CST sprouting and enhanced dieback following spinal cord injury. Representative photomicrographs $(\boldsymbol{A}, \boldsymbol{B})$ and quantification $(\boldsymbol{C}-\boldsymbol{E})$ of BDA mini-ruby-labeled CST in proximity of the lesion site of wt and $\mathrm{p} 53^{-1-}$ mice following spinal cord injury. $A$, Impaired CST sprouting in coronal sections $5 \mathrm{~mm}$ rostral to the lesion site in $\mathrm{p} 53^{-/-}$compared with wt mice is shown. Higher magnification images show CST labeling and sprouting in wt mice $(\boldsymbol{a}, \boldsymbol{b})$, which is strongly reduced in $\mathrm{p}^{-1-}$ (c). B, Photomicrographs of spinal cord parasagittal sections show CST collateral sprouting and retraction bulbs in the vicinity of the lesion in wt and $\mathrm{p}^{-1-}$ mice. Collateral sprouting is impaired while retraction bulbs are enhanced in $\mathrm{p} 53^{-/-}$ mice. High-magnification images show axonal sprouts in wt ( $\boldsymbol{a}$, arrows) and retraction bulbs ( $\boldsymbol{b}$, short arrows; $\boldsymbol{c}$ ). GFAP staining was used to determine the lesion border. The white dashed lines in $\boldsymbol{B}$ show the lesion border. Quantification of selected CST parameters displays a more pronounced dieback of $\mathrm{p} 53^{-1-}$ CST from the lesion site compared with wt mice (C); a decreased collateral sprouting $(\boldsymbol{D})$; and increased number of collapsing axons $(\boldsymbol{E})$ before the lesion site. All measurements were performed in tissues collected $28 \mathrm{~d}$ following spinal cord lesion. $n=6 \mathrm{wt}$ and $7 \mathrm{p} 53^{-1-}$ animals. Scale bar: $A, B$, Lower magnification, $500 \mu \mathrm{m}$; higher magnification, $40 \mu \mathrm{m}$. In $B$, D, Dorsal; $V$, ventral; $R$, rostral; $C$, caudal. For CST sprouting and bulbs indexes, values were normalized to the total number of BDA mini-ruby-labeled axons and expressed as averages \pm SEM. Student's $t$ test, ${ }^{*} p \leq 0.05$.

freshly purified microglia was plated at 150,000 cells per well in a 24-well plate. Cells were incubated under standard cell culture conditions for $48 \mathrm{~h}$ similar to the proliferation assay. At the end of this time period, the apoptosis assay was performed. Well media containing floating dead cells were removed and kept. Cells were detached after an incubation with $0.25 \%$ trypsin and the suspension added to the media from before. The staining protocol allows identification of Annexin $\mathrm{V}^{+}$(early apoptotic) and AxV/PI double-positive cells (late apoptotic and necrotic cells) by FACS analysis.

\section{Immunocytochemistry}

For immunocytochemistry, cells were plated in 96-well plates or $12 \mathrm{~mm}$ coverslips in 24-well plates maintained in standard culture conditions for $24 \mathrm{~h}$. Cell were fixed with $4 \%$ PFA and permeabilized with $0.1 \%$ Triton X. After several PBS washes, cells were incubated with primary antibody for

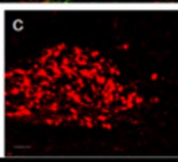

$30 \mathrm{~min}$ at room temperature or in some cases $90 \mathrm{~min}$ at $4^{\circ} \mathrm{C}$. After subsequent PBS washes, cells were incubated with secondary antibody for $30 \mathrm{~min}$ at room temperature. Cells were washed and stained with DAPI to visualize nuclei, and coverslips were mounted. The following antibodies were used: rat anti-CD11b (Serotec), rabbit anti-p53 (Novocastra), and rabbit anti-cleaved caspase (Cell Signaling).

Primary cortical neurons and transfections Briefly, cortices from 17- to 18-d-old embryos were cleaned from their meninges and blood vessels in Krebs'-Ringer's bicarbonate buffer containing $0.3 \%$ BSA. Cortices were minced and dissociated in the same buffer with 1800 $\mathrm{U} / \mathrm{ml}$ trypsin at $37^{\circ} \mathrm{C}$ for $20 \mathrm{~min}$. Following the addition of $200 \mathrm{U} / \mathrm{ml}$ DNase I and $3600 \mathrm{U} / \mathrm{ml}$ soybean trypsin inhibitor to the suspension, cells were triturated through a $5 \mathrm{ml}$ pipette. After the tissue was allowed to settle for 5-10 min, the supernatant was collected, and the remaining tissue pellet was retitrated. The combined supernatants were centrifuged through a $4 \%$ BSA layer, and the cell pellet was resuspended in NSM (neuronal seeding medium), which consisted of B27-Neurobasal medium (Invitrogen) supplemented with 1.1\% 100× antibiotic-antimycotic solution, $25 \mu \mathrm{M} \mathrm{Na}$ glutamate, $0.5 \mathrm{~mm}$ L-glutamine, and 2\% B27 supplement (Invitrogen). Cells were seeded at a density of $5 \times 10^{5}$ cells $/ \mathrm{ml}$ onto poly-Dlysine-coated $(70-150 \mathrm{kDa})$ 96-well plates (Corning) or $60 \mathrm{~mm}$ Petri dishes (Falcon; BD Biosciences Discovery Labware). Arabinofuranosyl cytidine (Ara-C) was added $24 \mathrm{~h}$ after plating $(5 \mu \mathrm{M})$. Briefly, transfections with CMV GFP or CMV p53-GFP plasmid DNA were performed using Lipofectamine 2000 (Invitrogen) $24 \mathrm{~h}$ after plating following standard procedures. Cells were fixed $72 \mathrm{~h}$ following transfection.

\section{Neurite outgrowth}

Neurite outgrowth in cortical neurons was evaluated by calculating the length of the longest process per cell. Measurements were taken from three individual experiments by two different operators. For each experimental condition, at least $30-40$ cells were counted. Cells were viewed using a CCD camera and analyzed with the image analysis software AxioVision 3.1 (Zeiss). Transfected neurons and neurites were identified by double labeling for GFP and $\beta 3$-tubulin.

\section{Statistical analysis}

Statistical analysis was performed using PASW Statistics 18 software. Student's $t$ test with or without Bonferroni's correction or repeated-measurement ANOVA was used as indicated.

\section{Results}

\section{p53 $3^{-l-}$ mice show impaired recovery of motor functions} following spinal cord injury

To investigate whether the transcription factor p53 plays a relevant role in the pathophysiological response following SCI, we first evaluated the effect of the absence of p53 on the recovery of motor functions following SCI in mice. wt and $\mathrm{p} 53^{-/-}$mice underwent a T10 spinal cord bilateral dorsal hemisection (Fig. $1 A$ ) and their functional recovery was evaluated for 4 weeks with a set of motor and sensory behavioral tasks, including the open 
A

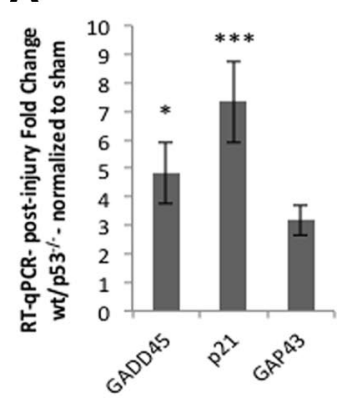

E

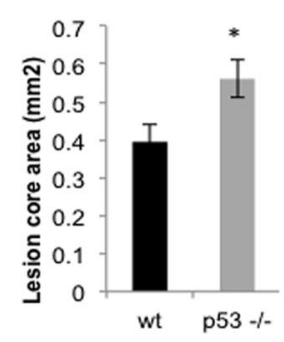

B

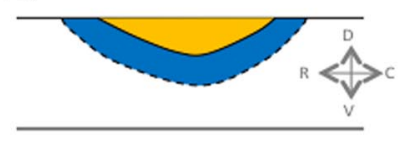

C
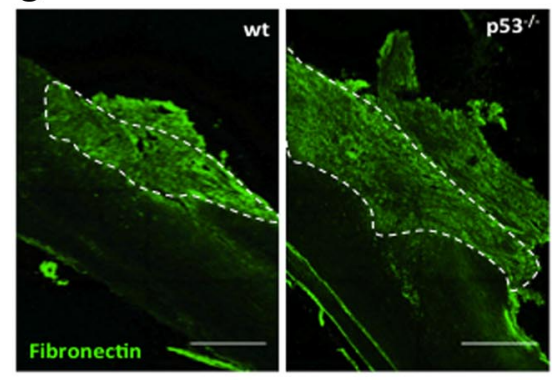

D

F

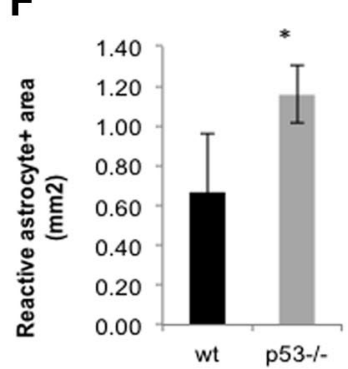

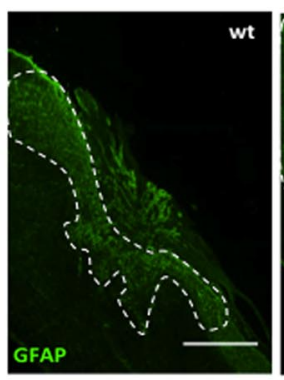

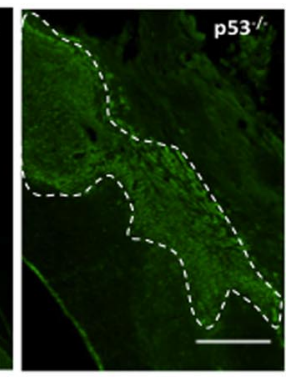

G
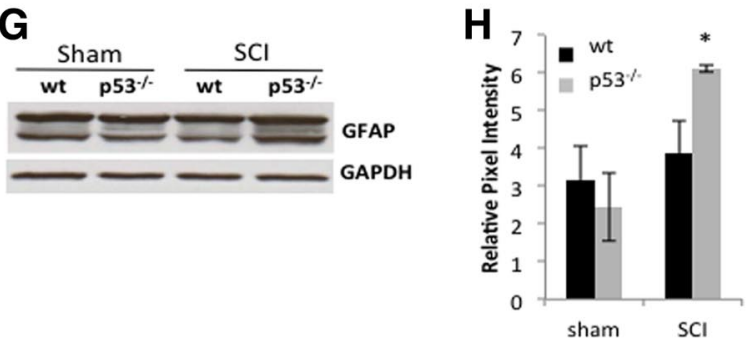

Figure 4. $\mathrm{p} 53$ is transcriptionally active and $\mathrm{p} 53^{-1-}$ mice display larger lesion core and reactive astrocyte area following spinal cord injury. $\boldsymbol{A}, \mathrm{GADD} 45, \mathrm{p} 21$, and GAP-43 mRNA levels are increased at the lesion site following spinal cord injury in wt compared with p53 ${ }^{-1-}$ mice. $\boldsymbol{B}$, Scheme of a spinal cord sagittal section. The yellow and blue forms represent the lesion core and the reactive astrocyte-positive areas, respectively. C, Representative pictures of fibronectin-immunopositive lesion core of wt and p53 ${ }^{-/-}$mice following spinal cord injury (dashed lines mark fibronectin-positive lesion site within the cord). $\boldsymbol{E}$, Quantification of fibronectin-immunopositive area shows a larger scar in p53 ${ }^{-1-}$ compared with wt mice following spinal cord injury. $\boldsymbol{D}$, Representative pictures of GFAP immunostaining show the reactive astrocytic area around the lesion core in $\mathrm{p} 53^{-\boldsymbol{-}}$ and wt mice (dashed lines mark reactive astrocyte-positive area). $\boldsymbol{F}$ - $\boldsymbol{H}$, Quantification of GFAP-immunopositive area $(\boldsymbol{F})$ and protein expression by immunoblotting analysis $(\boldsymbol{G}, \boldsymbol{H})$ show greater activation of astrocytes and GFAP expression, respectively, at the lesion site in $\mathrm{p}^{-1-}$ compared with wt mice following spinal cord injury, but not laminectomy. $I$, Fibronectin, collagen $1 \alpha 2$, and collagen $4 \alpha 1$ mRNA levels are increased at the lesion site following spinal cord injury in wt compared with p53 $3^{-1-}$ mice. Histological analysis was performed on five animals for each genotype. Western blot analysis was performed on pools of three animals for each genotype for each condition in triplicate. GAPDH protein expression levels were used for normalization in pixel intensity analysis. Both analyses were performed on tissues collected $28 \mathrm{~d}$ after injury. RT-qPCR fold change values are from six mice (lesion sites) for each condition and normalized to GAPDH and laminectomy control for each genotype before comparison between genotypes following the injury. Tissues were collected at $3 \mathrm{dpo}$. All values are averages \pm SEM. Student's $t$ test, ${ }^{*} p \leq 0.05,{ }^{* * *} p \leq 0.001$. In $\boldsymbol{B}, \mathrm{D}, \mathrm{Dorsal} ; \mathrm{V}$, ventral; R, rostral; $\boldsymbol{C}$, caudal. Scale bar: $\boldsymbol{C}, \boldsymbol{D}, 500 \mu \mathrm{m}$.

field, scored with the BMS (Basso et al., 2006), the grid walk, the automated CatWalk, and the Hargraeves' plantar heat test. Although $\mathrm{p} 53^{-1-}$ mice were indistinguishable from wt during the training period and the preinjury test sessions, they showed a significant impairment in the recovery of motor functions following spinal cord injury (Fig. $1 B-F$ ).

Specifically, in the open-field task, $\mathrm{p} 53^{-1-}$ mice scored significantly worse than wt at 21 and $28 \mathrm{~d}$ following SCI. The impairment was mainly due to the frequency of plantar stepping, the grade of coordination, the paw position during stance, and the degree of trunk instability (Fig. $1 B, C$ ). In the grid walk, $\mathrm{p} 53^{-/-}$mice placed the hindpaws less accurately than wt when crossing the grid, resulting in statistically significantly more mistakes at all time points tested after SCI (Fig. 1D). Furthermore, taking advantage of the automated CatWalk, we also analyzed parameters that allowed us to evaluate finer locomotor functions. In particular, the average speed of the walkway crossing as well as the average stride length of the hindpaws were significantly reduced in $\mathrm{p} 53^{-1-}$ compared with wt mice following SCI (Fig. 1E,F). Finally, to determine whether p53 was in- volved in the postinjury adaptation of the sensory response, we used the Hargraeves' heat plantar test. We did not observe a difference in the hindpaw withdrawal time between the two genotypes and between preoperation or postoperation at the tested time points (Fig. $1 G)$, suggesting that p53 does not play a major role in the rearrangement of the sensory fibers following SCI. The absence of a difference in wt mice between preoperative and postoperative time points is in accordance with the observation of Hill et al. (2009) for the dorsal spinal cord hemisection.

\section{p53 ${ }^{-1-}$ mice show increased CST dieback and reduced CST and 5-HT sprouting following spinal cord injury}

The degree of functional recovery following SCI depends on the reorganization and the formation of new circuits due to synaptic plasticity and collateral sprouting of lesioned and unlesioned descending tracts (Raineteau and Schwab, 2001; Cafferty et al., 2008).

Since the absence of p53 leads to a significant impairment in functional recovery following SCI, we investigated the role of p53 
on axonal sprouting of the functionally relevant serotoninergic (5-HT) fibers and the CST (Faden et al., 1988; Bregman et al., 1995; Saruhashi et al., 1996; Maier et al., 2009). Indeed, by 5-HT immunostaining, we observed a significant reduction in sprouting of the 5-HT axons in the laminae VII and IX of the gray matter and in the IML at 1,3 , and $5 \mathrm{~mm}$ below, but not $2 \mathrm{~mm}$ above, the injury site in $\mathrm{p} 53^{-/-}$compared with wt mice (Fig. $2 A-D$ ). The layer V neurons were labeled by BDA tracer injection in the SMC, and, at the spinal cord level, the CST sprouting and retraction bulb indexes were calculated normalizing the total number of sprouts or retraction bulbs to the total number of labeled axons, since the total number of BDA-labeled axons varies from animal to animal (Schnell and Schwab, 1993; Simonen et al., 2003). We first found that $\mathrm{p} 53^{-/-}$mice displayed reduced CST sprouting 5 $\mathrm{mm}$ above the injury site, suggesting impaired axonal plasticity compared with wt (Fig. 3A). Then, we observed a more pronounced dieback of the CST, decreased sprouting, and an increased number of retraction bulbs just rostral to the lesion site in p53 $3^{-1-}$ mice (Fig. 3B-E).

Collectively, these data support a role for p53 in the regulation of 5-HT and CST sprouting following SCI and partially explain the impairment in the recovery of motor function following SCI in absence of p53. However, they do not exclude that p53 may influence the inhibitory extrinsic response to the injury, which affects growth cone collapse and retraction of the damaged axons and therefore the degree of axonal dieback and sprouting (Yiu and He, 2006).

\section{p53 $3^{-/-}$mice display increased number of activated microglia/macrophages and enhanced scar formation following spinal cord injury}

Given the role of p53 in the cell cycle arrest checkpoint in dividing cells and in apoptosis in cells under several stressors (Pietenpol and Stewart, 2002; Oren, 2003), we hypothesized that p53 would also affect the formation of the glial scar. The glial scar is in fact highly dependent upon the proliferation of reactive astrocytes and microglia/blood-derived macrophages as well as on the degree of cell death at the lesion site (Tian et al., 2006, 2007; Wu et al., 2011).

In accordance with previous data (Saito et al., 2000), high nuclear expression of p53 in the spinal cord is induced following injury in a time-dependent manner, with a peak between 2 and $3 \mathrm{~d}$ after injury, in several glial cells such as astrocytes and activated microglia/macrophages (data not shown). More importantly, we ascertained by RT-qPCR that p53 was transcriptionally active, as shown by an enhanced expression of p53 target genes p21 (cell cycle arrest gene), GADD-45 (DNA damage sensor), and GAP-43 (axonal outgrowth and regeneration gene) in wt versus $\mathrm{p} 53^{-1-}$ cords after SCI (Fig. 4A).

To investigate the role of $\mathrm{p} 53$ on the scar formation, we performed immunohistochemistry (IHC) for fibronectin and GFAP on spinal cord sections from $\mathrm{p} 53^{-1-}$ versus wt mice, $28 \mathrm{~d}$ following SCI. We observed an enlarged deposition of fibronectin resulting in a bigger lesion core area and a larger area of reactive astrocytes surrounding the lesion borders in $\mathrm{p} 53^{-/-}$compared with wt spinal cords (Fig. $4 B-F$ ). Furthermore, immunoblot analysis of the lesion site showed an increased expression of GFAP in absence of p53 compared with wt following SCI, but not in laminectomy control conditions (Fig. 4G,H).

As observed by RT-qPCR analysis of spinal cord lesion site, the absence of p53 resulted in an increased gene expression of several scar-related genes, including fibronectin, collagen $1 \alpha 2$ and collagen $4 \alpha 1$ (Fig. $4 I$ ), but not of others such as TGF $\beta 1$, tenascin-c, or neurocan $3 \mathrm{~d}$ following SCI (data not shown). Fur-

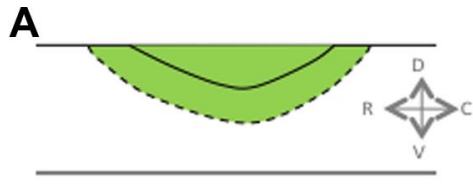

B
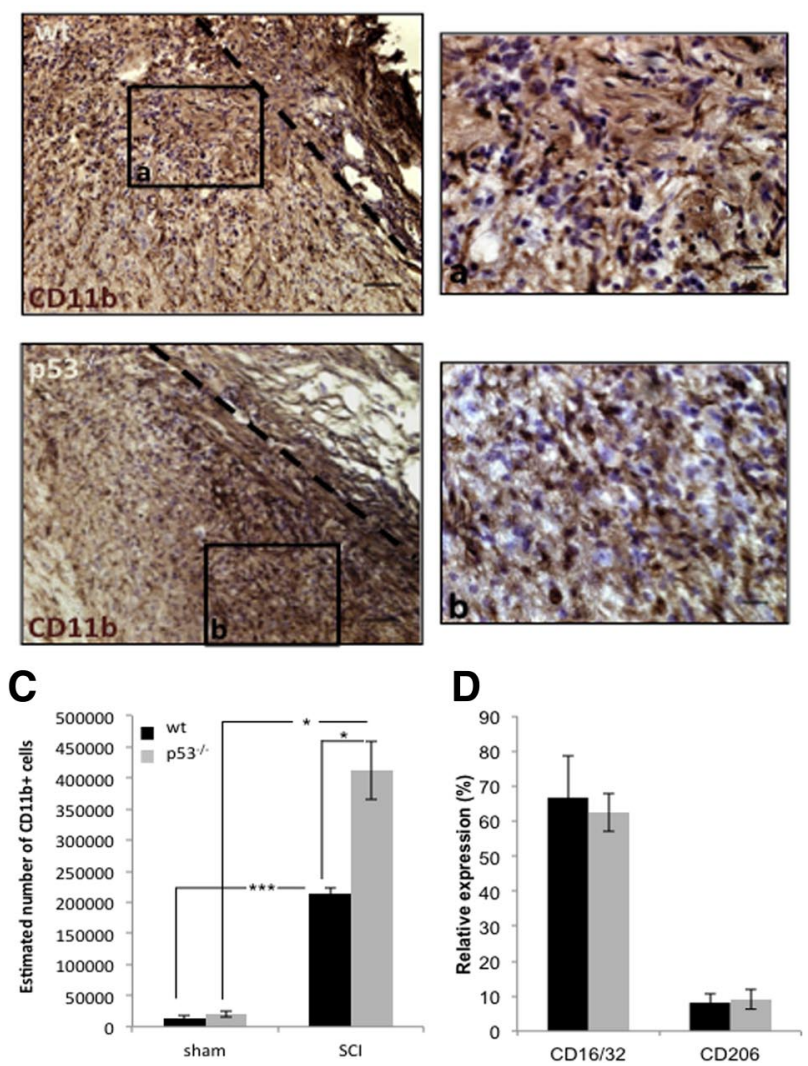

Figure 5. The absence of $\mathrm{p} 53$ results in an increased number of activated microglia/macrophages and does not change the ratio of M1/M2 populations at the lesion site following spinal cord injury. $\boldsymbol{A}$, Scheme of a spinal cord sagittal section. The green area represents the lesion site and the area of interest analyzed. $\boldsymbol{B}$, Representative pictures of CD11b-immunopositive cells at the lesion site of wt and $p 53^{-1-}$ mice following spinal cord injury. The dashed line delimits the lesion core border. $\boldsymbol{a}$ and $\boldsymbol{b}$ are higher magnifications of the boxed areas in $\boldsymbol{B}$ of wt and $\mathrm{p} 53^{-1-}$ cords, respectively. C, Stereological estimation of the number of CD11b-immunopositive cells at the lesion site shows a bigger population in $\mathrm{p} 53^{-/-}$compared with wt mice following spinal cord injury, but not in laminectomy control condition. D, The bar graph shows the quantification of the expression of the antigens CD16/32 (M1) and CD206 (M2) relative to the expression of Iba1 in wt and $\mathrm{p} 53^{-/-}$mice at the lesion site following $S C I$. In $A, D$, Dorsal; $V$, ventral; $R$, rostral; C, caudal. Scale bars: $\boldsymbol{B}$, Low-magnification pictures, $50 \mu \mathrm{m}$; high-magnification pictures, 20 $\mu \mathrm{m}$. All tissues were collected $28 \mathrm{dpo}$. All values are averages $\pm \mathrm{SEM}$, and the analysis was performed on three animals for each genotype for each condition in a blinded fashion. Student's $t$ test with Bonferroni's correction, ${ }^{*} p \leq 0.05,{ }^{* * *} p \leq 0.001$.

thermore, immunoblot analysis of the protein expression levels of the abundant chondroitinase sulfate proteoglycan (CSPG) aggrecan was not significantly different between the two genotypes at 3 and $28 \mathrm{~d}$ after SCI (data not shown). These data suggest an involvement of p53 in regulation of the expression of fibrotic scar-associated extracellular matrix components but not of proteoglycans (Moore and Goldberg, 2011).

Given that glial scar formation is in part dependent upon the postinjury inflammatory response, including the contribution of rapidly dividing activated microglia and macrophages, and the relevance of this response in the recovery of motor functions (Popovich et al., 1999; Jones et al., 2005; Loane and Byrnes, 2010), we assessed 
the potential influence of p53 on the number of activated microglia and macrophages following SCI. To this end, we performed anti-CD11b IHC on spinal cord sections of p53 $3^{-1-}$ and wt mice, $28 \mathrm{~d}$ following SCI, and we stereologically counted the number of activated microglia/macrophages. Importantly, we found a significant increase in the number of these cells at the lesion site in p53 $3^{-/-}$versus wt spinal cords (Fig. $5 A-C$ ), suggesting the presence of a more aggressive postinjury inflammatory response. Notably, we did not observe any difference in the number of $\mathrm{CD} 1 \mathrm{~b}^{+}$cells between genotypes following laminectomy control surgery (Fig. 5C). As the polarization of microglia/macrophages toward an M1 or M2 phenotype can influence their proinflammatory properties (Kigerl et al., 2009), we investigated whether p53 may regulate the commitment toward M1 versus M2 phenotype of microglia/macrophages following SCI. To this end, we quantified the percentage of the CD16/32- and CD206positive cells at the lesion site $28 \mathrm{~d}$ following SCI. We did not observe any difference between $\mathrm{p} 53^{-1-}$ and wt mice, ruling out a possible role of p53 in regulating the polarization of microglia/macrophages following SCI (Fig. 5D).

p53 regulates glial proliferation at the lesion site following spinal cord injury Furthermore, we investigated the potential role of p53 in the regulation of the proliferation of astrocytes and microglia/ macrophages in vivo. We performed immunoblotting for the cell proliferation marker PCNA and double immunofluorescent staining for GFAP/Ki67 and $\mathrm{CD} 11 \mathrm{~b} / \mathrm{Ki} 67$ at $3 \mathrm{~d}$ following SCI on wt and $\mathrm{p} 53^{-1-}$ spinal cords, a time point at which nuclear p53 is highly expressed (Saito et al., 2000). We observed an increased protein expression of PCNA at the lesion site in $\mathrm{p} 53^{-1-}$ compared with wt mice following SCI, but not following laminectomy (Fig. 6A,B), and an increased number of CD11b/Ki67, but not GFAP/Ki67 double-positive cells in p53 $3^{-1-}$ compared with wt spinal cords after SCI (Fig. 6E-J). Importantly, PCNA expression was not detectable by Western blotting (WB) analysis at $28 \mathrm{~d}$ after injury, when the number of double-positive GFAP/Ki67 and CD11b/ Ki67 cells was also dramatically reduced in a comparable fashion in both genotypes (data not shown), supporting the concept that p53 is transiently activated in proliferating cells in the injured spinal cord.

In addition, to assess a role for p53 in the regulation of cell death at the lesion site following SCI, we performed immunoblotting analysis for procaspase- 3 and cleaved caspase- 3 on protein extracts form the lesion site from $\mathrm{p}^{-1-}$ and wt spinal cords
A
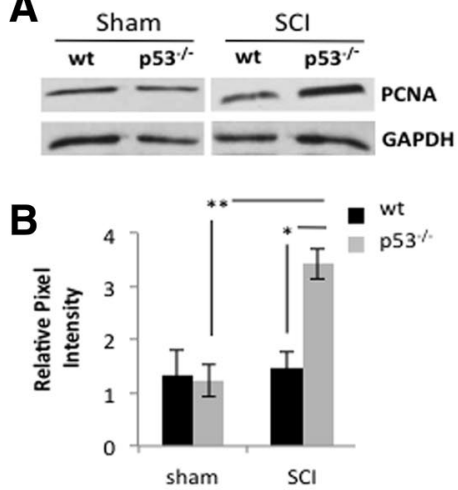

E

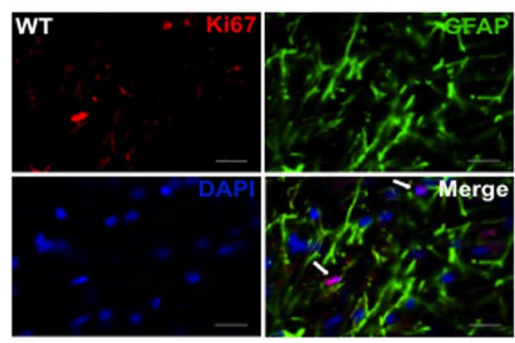

G

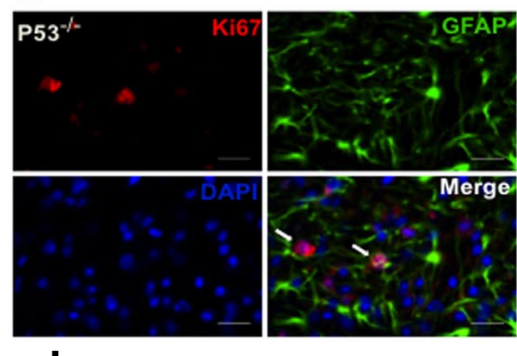

I

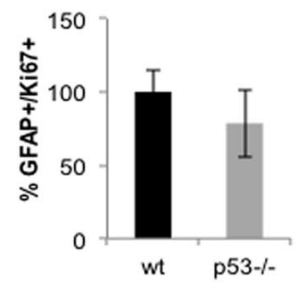

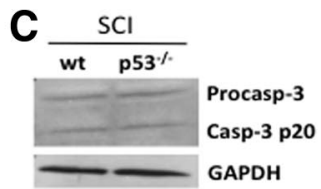

D

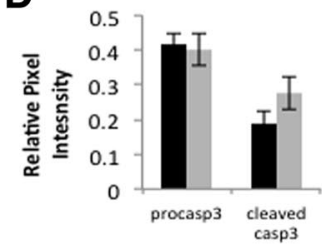

F

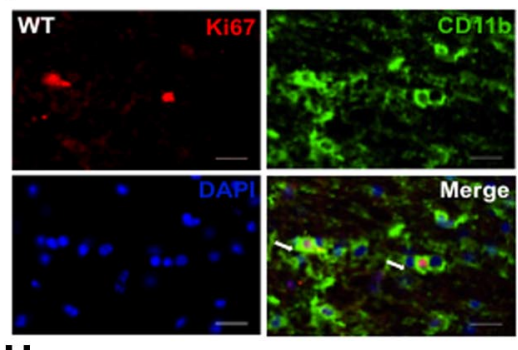

H

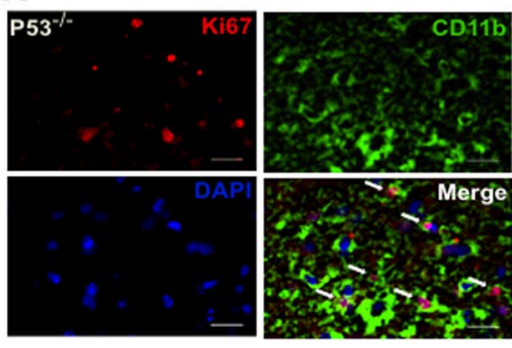

$\mathbf{J}$

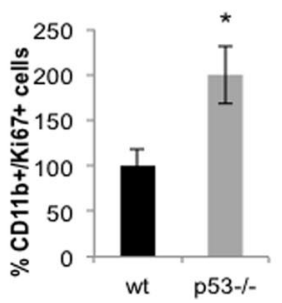

Figure 6. p53 regulates proliferation of microglia/macrophages but not of astrocytes nor apoptosis at the lesion site in the acute phase following spinal cord injury. $\boldsymbol{A}, \boldsymbol{B}$, Following spinal cord injury, PCNA protein expression is enhanced in $\mathrm{p} 53^{-1-}$ mice compared with wt as shown by immunoblotting $(\boldsymbol{A})$ and its quantification $(\boldsymbol{B})$. Following laminectomy, PCNA protein expression is comparable between genotypes $(\boldsymbol{A}, \boldsymbol{B}) . \boldsymbol{C}, \boldsymbol{D}$, Immunoblotting $(\boldsymbol{C})$ and its quantification $(\boldsymbol{D})$ show that procaspase-3 and cleaved caspase-3 protein expression is comparable between genotypes following spinal cord injury. $\boldsymbol{E}-\boldsymbol{J}$, Double immunofluorescence for $\mathrm{GFAP}^{+} / \mathrm{Ki} 67^{+}$and $\mathrm{CD} 11 \mathrm{~b}^{+} / \mathrm{Ki}_{67}{ }^{+}$in p53 $3^{-/-}$and wt spinal cords at 3 d postinjury. GFAP ${ }^{+}(\boldsymbol{E}, \boldsymbol{G})$ and $\mathrm{CD} 11 \mathrm{~b}{ }^{+}(\boldsymbol{F}, \boldsymbol{H})$ cells show coexpression of the proliferation marker $\mathrm{Ki} 7^{+} .{\mathrm{CD} 11 \mathrm{~b}^{+} / \mathrm{Ki}^{+} 7^{+}(\boldsymbol{J}) \text { but not GFAP }}^{+} / \mathrm{Ki} 7^{+}(\boldsymbol{I})$ cells are more numerous in p53 $3^{-1-}$ compared with wt mice. $n=3-4$ for each genotype and condition. Tissues for analysis of proliferation and apoptosis were collected 3 and $1 \mathrm{~d}$ following surgery, respectively. Cell counting was performed in blinded fashion. Values are averages \pm SEM, and relative pixel intensity and percentage values were normalized to GAPDH or the total number of counted GFAP ${ }^{+}$or $\mathrm{CD} 11 \mathrm{~b}^{+}$, respectively. Student's $t$ test (with Bonferroni's correction in $\boldsymbol{B}$ ): ${ }^{*} p \leq 0.05,{ }^{* *} p \leq 0.01$. Scale bar: $\boldsymbol{E}-\boldsymbol{H}, 20 \mu \mathrm{m}$.

at 1 and $3 \mathrm{~d}$ following SCI, a time window of high expression of cleaved caspase-3 (Knoblach et al., 2005). We did not observe any difference in caspase-3 protein expression levels between the two genotypes at $1 \mathrm{~d}$ (Fig. 6C,D), while we did not detect cleaved caspase- 3 at $3 \mathrm{~d}$ after injury (data not shown), supporting a specific role for $\mathrm{p} 53$ in the regulation of cell proliferation rather than apoptosis in this spinal cord injury model.

So far, we have shown that p53 plays an important role in regulating axonal sprouting and glial proliferation as well as in 

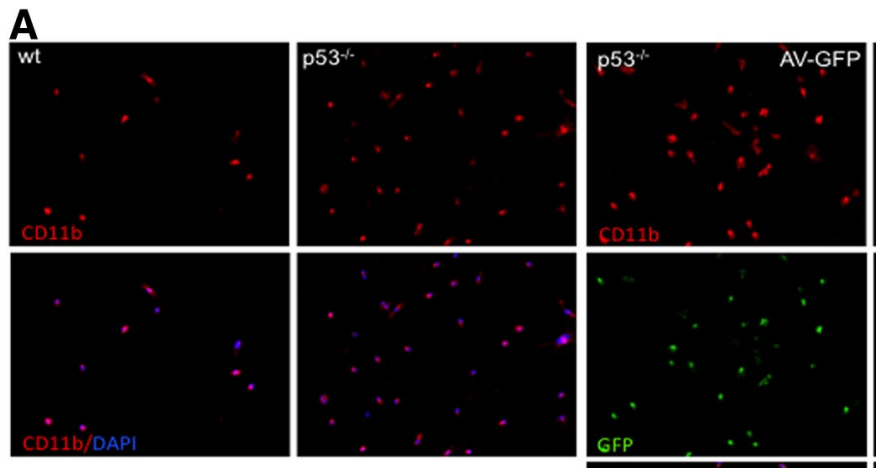

B
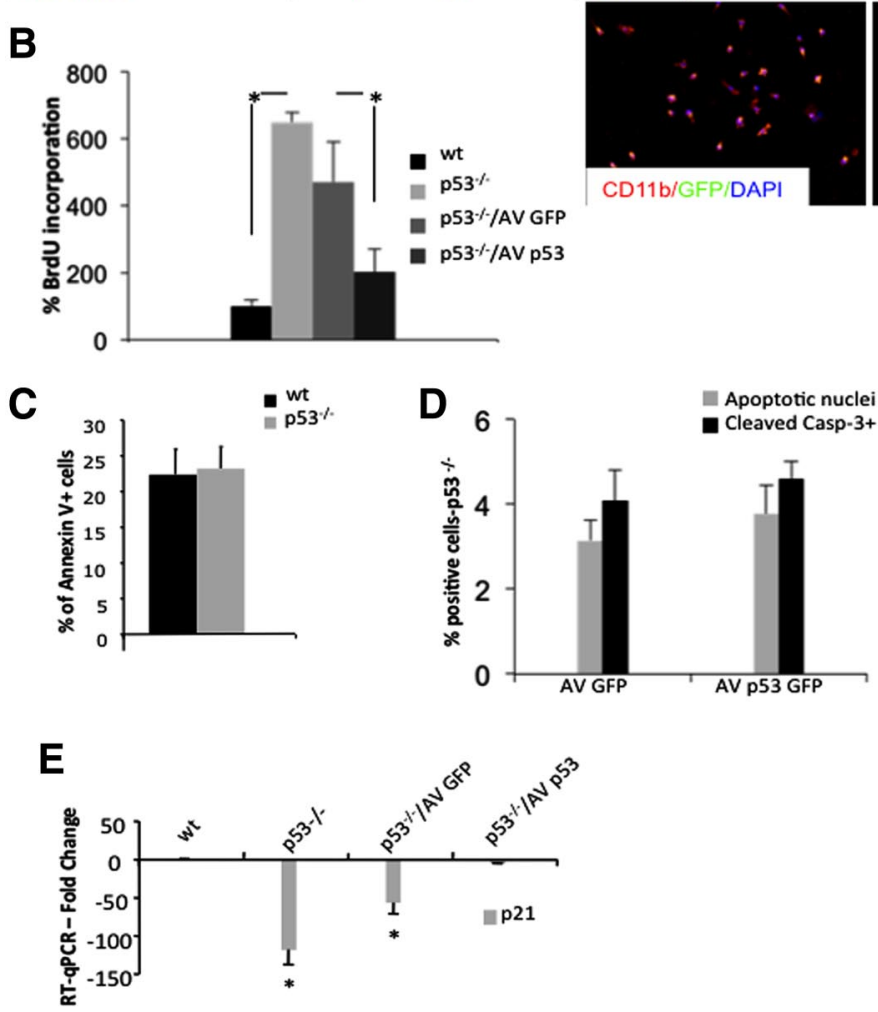

Figure 7. p53 controls microglia proliferation but not apoptosis in vitro. $\boldsymbol{A}$, Representative micrographs of CD11 ${ }^{+}$microglia show increased proliferation of $\mathrm{p} 53^{-1-}$ cells in basal culture conditions. Reconstitution of p53 expression in $\mathrm{p} 53^{-/-}$microglia by AV-p53GFP inhibits the increase in proliferation. Scale bar, $100 \mu \mathrm{m}$. B, BrdU incorporation is significantly increased in p53 $3^{-1-}$ microglia compared with wt, and AV-p53GFP significantly inhibits this increase compared with AV-GFP. C, Bar graph of percentage of Annexin V-positive microglia in cultures does not show significantly different apoptosis in wt compared with p53 ${ }^{-1-}$ cells, as determined by FACS analysis. D, 0verexpression of p53 via AV-p53GFP in p53 $3^{-1-}$ microglia does not induce significant levels of apoptosis compared with AV-GFP-infected cells. Graphs showing number of cells with condensed nuclei and positive for cleaved caspase-3. $n=3-4$ for each genotype and each condition. All measures are mean values \pm SEM. $\boldsymbol{E}, \mathrm{qRT}-\mathrm{PCR}$ analysis of $\mathrm{p} 53$ target gene $\mathrm{p} 21$ shows a significantly downregulation of mRNA expression of this gene in cultured $p 53^{-1-}$ microglia. AV-p53 infection increases p21 mRNA level to that of wt controls. Mean fold change above wt controls \pm SEM; $n=3$. Student's $t$ test, ${ }^{*} p \leq 0.05$.

scar formation following SCI. However, it is not clear yet whether p53 is able to directly control axonal sprouting following spinal cord injury or whether impairment in sprouting and enhanced axonal dieback are only due to the increased glial scar.

\section{p53 regulates microglial proliferation but not apoptosis}

To clarify the cellular mechanisms through which p53 may regulate the number of microglia/macrophages after SCI, we decided to investigate the role of p53 in the regulation of their proliferation and survival. To this end, we cultured primary microglia from wt and $\mathrm{p} 53^{-1-}$ mice and performed BrdU incorporation experiments. We observed an increase in proliferation of $\mathrm{p} 53^{-1-}$ cells that could be significantly reduced by viral expres-
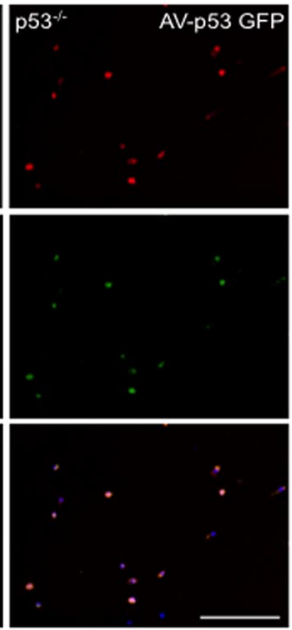

sion of Adeno-p53 in p53-1- cells (Fig. $7 A, B$ ), showing a relevant $\mathrm{p} 53$-dependent effect on the proliferation of microglia. Furthermore, FACS analysis of apoptotic Annexin V-positive microglial cells excluded a role for $\mathrm{p} 53$ in apoptosis of cultured microglia (Fig. 7C). Similarly, viral expression of $\mathrm{p} 53$ in $\mathrm{p} 53^{-1-}$ cells did not affect apoptosis of those cells (Fig. 7D), but only decreased their proliferation (Fig. $7 A, B$ ). In immunocytochemistry experiments, we also assessed that p53 was expressed in cultured microglia in basal conditions and that the expression was strongly enhanced by p53 adenoviral infection (data not shown).

Importantly, to evaluate p53 transcriptional activity in cultured microglia, we measured the expression of p21, a readout of p53 transcription and a cell cycle arrest gene (el-Deiry et al., 1993). We found a significant reduction of p21 expression in $\mathrm{p}^{2} 3^{-1-}$ microglia, which was significantly rescued by expression of p53, paralleling the observed arrest in cell proliferation (Fig. 7E).

\section{Viral expression of p53 in layer V neurons enhances CST sprouting following spinal cord injury}

To assess whether the more pronounced impairment in axonal sprouting of supraspinal descending fibers following $\mathrm{SCI}$ observed in $\mathrm{p} 53^{-1-}$ mice was at least partially due to a direct role of p53 in the outgrowth of CST axons, we reintroduced $\mathrm{p} 53$ in the SMC of $\mathrm{p} 53^{-1-}$ mice. A dual CMV promoter adenovirus driving p53 and GFP or a control GFP adenovirus were stereotaxically injected in the SMC of $\mathrm{p}^{-1-}$ mice at the time of a T10 spinal cord bilateral dorsal hemisection (Fig. $8 A$ ). CST axons were traced with BDA, and the CST sprouting was evaluated at $28 \mathrm{~d}$ following SCI. p53 viral expression, as detected by the reporter gene GFP, was visible as early as at $72 \mathrm{~h}$ in the layer $\mathrm{V}$ neurons (Fig. $8 \mathrm{~B}$ ) and lasted until $28 \mathrm{~d}$ after injury (Fig. $8 C$ ).

The reintroduction of $\mathrm{p} 53$ in the SMC of $\mathrm{p}^{2} 3^{-1-}$ mice resulted in a significant increased CST sprouting $5 \mathrm{~mm}$ above the lesion site, suggesting enhanced axonal plasticity (Fig. $8 D$ ). Importantly, p53 overexpression increased the number of axonal collateral sprouts rostral to the lesion site (Fig. $8 E$ ), also resulting in an intricate net of sprouts, mostly in the white matter (Fig. 8D). The observed sprouts rostral to the lesion often showed a growth cone at the end and a tortuous course, according to some of the criteria to identify regrowing axons (Steward et al., 2003). However, in this rescue experiment on a $553^{-1-}$ background, we did not observe a statistically significant difference in the number of axonal sprouts below the injury site compared with $\mathrm{p}^{-1-}$ mice injected with the control GFP adenovirus (Fig. $8 F$ ). The inability of these mice to significantly regrow the CST 
A

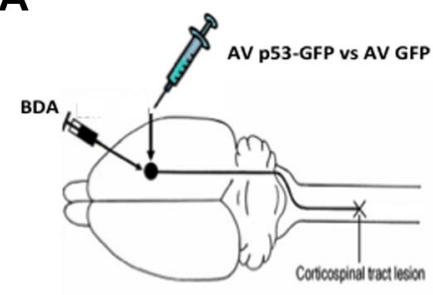

C

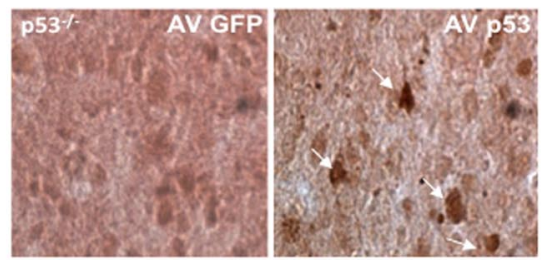

D

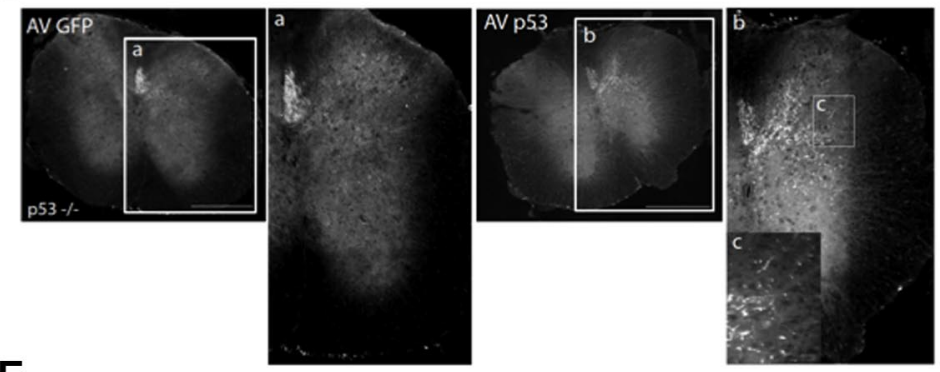

E
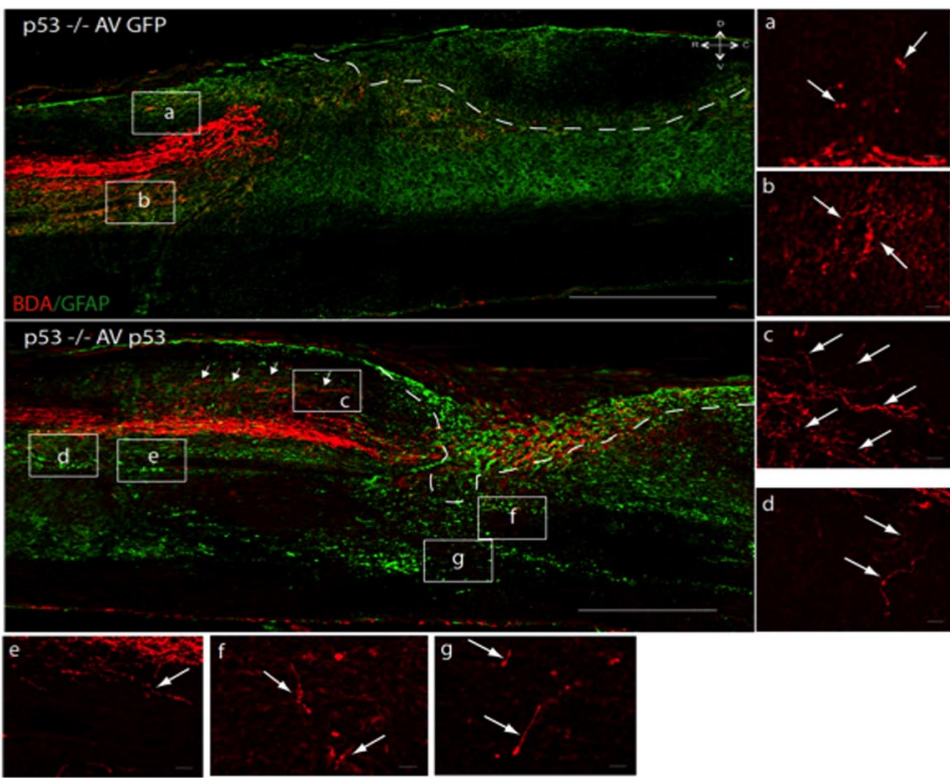

d
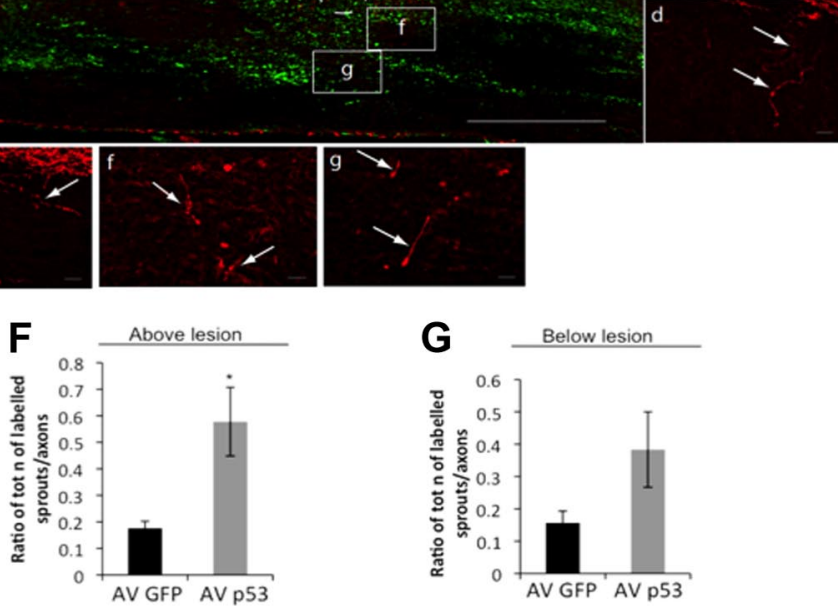

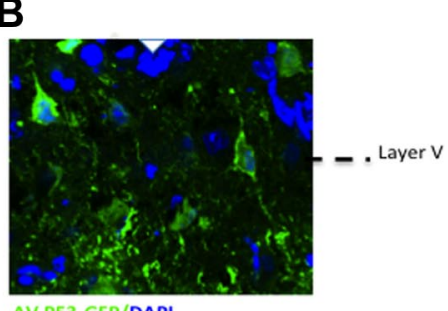

AV P53-GFP/DAPI

below the lesion site could be due to the highly inhibiting environment that develops in the absence of p53. Importantly, this experiment suggests that p53 is required to directly modulate CST axonal sprouting in vivo following SCI.

Finally, to further ascertain whether rescue of $\mathrm{p} 53$ expression on a $\mathrm{p} 53^{-1-}$ background leads to recovery of neurite outgrowth through the modulation of a neuronal intrinsic mechanism, we performed p53 rescue experiments in cultured primary cortical neurons. Embryonic cortical neurons (E18) from wt and $\mathrm{p} 53^{-1-}$ mice were transfected with GFP (wt), p53-GFP, or GFP $\left(\mathrm{p} 53^{--}\right)$, and neurite length was analyzed $72 \mathrm{~h}$ after transfection. Measurement of neurite outgrowth in transfected GFP-positive cells showed that $\mathrm{p} 53^{-1-}$ neurons had an impairment in neurite length (length of longest neurite) that could be fully rescued by overexpression of p53-GFP (Fig. 9A,B).

Overall, our data support a model in which $\mathrm{p} 53$ plays a dual role in the regulation of both the neuronal intrinsic and glial extrinsic responses following SCI.

\section{Discussion}

Poor functional recovery following $\mathrm{SCI}$ is due to both the development of an inhibitory glial environment that limits axonal

\section{$\leftarrow$}

p53-immunopositive layer V neurons. Counterstaining, Eosin. $D$, Coronal sections $5 \mathrm{~mm}$ rostral to the lesion site showing BDA mini-ruby-labeled CST in $\mathrm{p}^{-/-}$mice following spinal cord lesion. $\mathrm{p} 53^{-1-}$ mice were stereotaxically injected in the SMC with AV-p53 or a AV-GFP control virus. Shown is an increased CST sprouting in $p 53^{-1-}$ mice injected with AV-p53 compared with AV-GFP. E, Photomicrographs of spinal cord parasagittal sections in $\mathrm{p}^{-1-}$ mice injected with AV-GFP or AV-p53 following spinal cord injury. Representative pictures of BDA-labeled CST in proximity of the lesion site show enhanced CST collateral sprouting in $\mathrm{p53} 3^{-/-}$mice injected with AV-p53 compared with AV-GFP. Lesion borders were identified by GFAP staining. $\boldsymbol{a}-\boldsymbol{g}$, High magnifications showing collateral sprouting of boxed areas of the CST of a p53 $3^{-1-}$ mouse injected with AV-GFP or AV-p53. Of note, in c is displayed a very dense net of collateral sprouts running above the main CST bundle. The arrows indicate collateral sprouts. The dashed white lines mark the lesion borders. Scale bars: $D, E$, Lower magnification, $500 \mu \mathrm{m}$; higher magnification, $30 \mu \mathrm{m}$. In $E$, D, Dorsal; V, ventral; $R$, rostral; $C$, caudal. $\boldsymbol{F}, \boldsymbol{G}$, Quantification of sprouting index shows an increased collateral sprouting $(\boldsymbol{F})$ above the lesion site, while the sprouting index $1 \mathrm{~mm}$ below the injury site $(\boldsymbol{G})$ does not statistically significantly change in AV-p53 versus AV-GFP-injected p53 ${ }^{-1-}$ mice. All measurements were performed from tissues collected $28 \mathrm{~d}$ following spinal cord lesion and viral injection in the SMC. CST sprouting was evaluated on seven AV-GFP and AV-p53-injected animals, respectively. All measurements were normalized to the total number of BDA mini-ruby-labeled axons, and quantification was performed in blinded fashion. Values are expressed as averages \pm SEM. Student's $t$ test, ${ }^{*} p \leq 0.05$.

Figure 8. CST sprouting can be rescued in $\mathrm{p} 53^{-/-}$mice by viral expression of $\mathrm{p} 53$ in the SMC following spinal cord injury. $\boldsymbol{A}$ Scheme of stereotaxic delivery of BDA and viral construct in the mouse SMC. $\boldsymbol{B}$, Representative immunofluorescence micrograph shows expression of p53-GFP in the SMC $72 \mathrm{~h}$ after stereotaxic viral injection (white arrowhead, injection site). C, Immunoperoxidase staining shows $\mathrm{p} 53$ expression in the SMC of $p 53^{-1-}$ mice $28 \mathrm{~d}$ after stereotaxic $\mathrm{p} 53$ viral delivery. The arrows show 


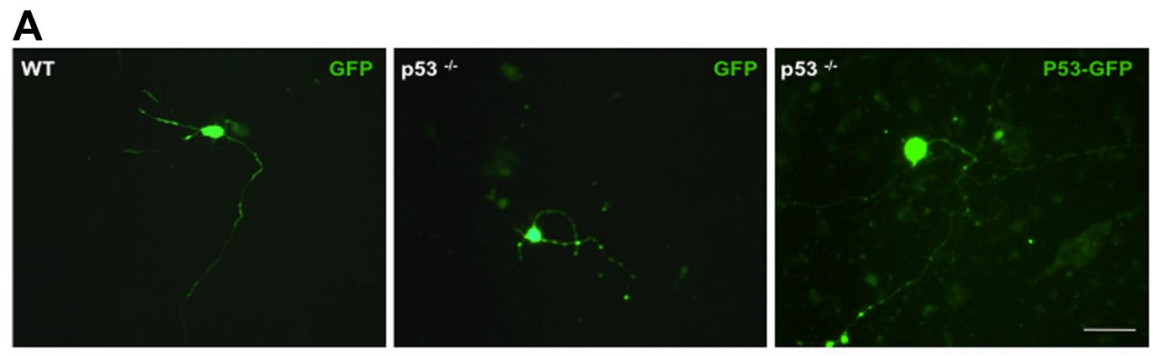

B

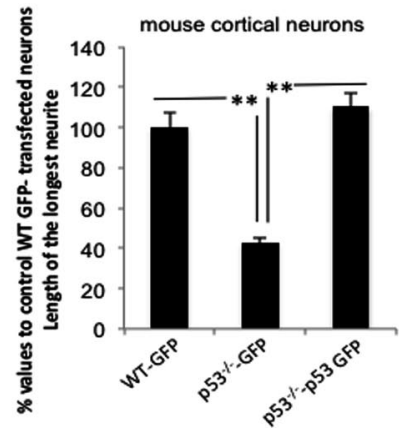

Figure 9. Rescue of $\mathrm{p} 53$ expression in $\mathrm{p} 53^{-1-}$ primary cortical neurons enhances neurite outgrowth. $\boldsymbol{A}$, Cultured primary mouse cortical neurons (E18) from wt or $\mathrm{p} 53^{-1-}$ mice were transfected at day 1 in vitro for $72 \mathrm{~h}$ with either GFP (wt), p53-GFP, or GFP $\left(p 53^{-1-}\right)$. Both GFP and anti- $\beta 3$-tubulin immunostaining were used to detect transfected neurons. Representative images of transfected neurons show that $\mathrm{p} 53^{-1-}$ neurons have impaired neurite outgrowth compared with wt and that overexpression of p53-GFP on a $553^{-1-}$ background restores neurite outgrowth to wt levels. $\boldsymbol{B}$, Bar graphs show quantification of neurite outgrowth (length of the longest neurite) following transfection expressed as average percentage values of control GFPtransfected cells. Data were obtained from three different experiments for $\sim 90$ neurons total counted for each condition. Student's $t$ test, ${ }^{* *} p \leq 0.01$.

sprouting and regeneration (Silver and Miller, 2004; Yiu and He, 2006) and to the limited intrinsic neuronal capacity to regrow damaged axons (Di Giovanni, 2009; Moore and Goldberg, 2011). Our findings suggest that the transcription factor p53 modulates both the extrinsic spinal inhibitory environment and the intrinsic capacity of CNS neurons affecting the recovery of motor function in response to a traumatic event.

We have previously found that p53 can occupy the promoters and drive the expression of a number of genes involved in neurite and axonal outgrowth such as Coronin 1b, Rab13 (Di Giovanni et al., 2006), and GAP-43 (Tedeschi et al., 2009a; Floriddia et al., 2011). Moreover, p53 transcriptionally enhances the expression of cGKI, thereby inhibiting semaphorin 3A-dependent growth cone collapse in primary cortical and dorsal root ganglia neurons (Tedeschi et al., 2009b). p53 also mediates transcriptionindependent pro-outgrowth pathways, by inhibiting local ROCK (Rho-associated protein kinase) activity at the growth cone counteracting growth cone collapse (Qin et al., 2009). Interestingly, semaphorin 3A-mediated growth cone collapse leads to truncation of phosphorylated active p53 via m-calpain, leading to Rho kinase activation, which is antagonized by phosphorylated p53 (Qin et al., 2010).

Here, we show for the first time that p53 is needed for physiological sprouting of 5-HT and corticospinal axons following SCI. p53 ${ }^{-1-}$ mice display a more pronounced dieback of the CST axon bundle and a reduced collateral sprouting compared with the already limited spontaneous sprouting response of the CST that occurs in adult wild-type animals after transection (Schnell and Schwab, 1993). We also found that sprouting of 5-HT fibers below the lesion site is reduced in absence of p53. As previously described, the degree of 5-HT spinal sprouting as well as sero- toninergic transmission below the injury site strongly correlate with the recovery of locomotor function of the hindlimbs following experimental SCI (Faden et al., 1988; Bregman et al., 1995; Saruhashi et al., 1996; Maier et al., 2009). Together with our data, this suggests a role for p53 in the regulation of axonal regrowth and plasticity remodeling of the damaged spinal cord that leads to partial recovery of motor function.

The impaired sprouting of supraspinal descending fibers in $\mathrm{p} 53^{-1-}$ mice is likely both a consequence of the abnormal inhibitory glial scar at the lesion site and of a role for p53 in the intrinsic neuronal plastic response to injury, as our gain-offunction experiments both in cultured neurons and in vivo in the SMC suggest. In fact, delivery of p53 in neurite outgrowthdeficient $\mathrm{p} 53^{-/-}$cultured cortical neurons restores physiological neurite outgrowth, and more importantly, viral overexpression of $\mathrm{p} 53$ in the SMC of $\mathrm{p} 53^{-1-}$ mice reestablishes and boosts the physiological sprouting plastic response that is very limited in wild-type CST. In fact, following rescue of p53 expression, transected CST axons show more sprouts and branches near the amputation site preferentially but not exclusively in the white matter facing the upper part of the cord where the dorsal columns physiologically run. Importantly, as expected from such a rescue experiment on a null background, we did not observe CST regeneration nor significantly enhanced axonal sprouting below the injury site. Nevertheless, the CST collateral sprouting above the injury site suggests an important role for $\mathrm{p} 53$ in axonal plasticity following SCI.

After spinal cord injury, cell cycle activation in neurons and glial cells is a crucial event that contributes to secondary damage, such as tissue loss and activation of astrocytes and microglia, negatively affecting the recovery of motor function (Di Giovanni et al., 2003; Byrnes et al., 2007). Here, we report that p53 is required to maintain the proliferation of microglia/macrophages under check, providing evidence for a further novel nonneuronal role for p53 following SCI. This effect on cell cycle is specifically dependent upon $\mathrm{p} 53$ as demonstrated by the gain-offunction experiments in which p53 overexpression can restore microglia proliferation to wt levels in $\mathrm{p} 53^{-1-}$ cells. The main contribution of $\mathrm{p} 53$ to the control of proliferation is likely due to the marked downregulation of p21 in p53 $3^{-1-}$ cells, which p53 overexpression promptly rescues along with reducing proliferation. Indeed, p21 is a well established specific p53-transcriptional target in a variety of cell types and tissues (el-Deiry et al., 1993; Missero et al., 1996) and a powerful cell cycle inhibitor via antagonism of CDK 2/4/6 (Johnson and Walker, 1999). Importantly, p53 does not seem to affect cell survival in these cells as shown by in the analysis of apoptotic nuclei and caspase- 3 expression. This is in agreement with the evidence that p53-dependent cell death is typically present only in highly damaged cells, for example following high levels of genotoxic and oxidative stress or growth factor deficiency, which are known to trigger p53-dependent ap- 
optosis (Aloyz et al., 1998; Sakaguchi et al., 1998; Culmsee and Mattson, 2005; Liebermann et al., 2007).

Following spinal cord injury, the inflammatory response plays a pivotal role in contributing to secondary damage and crafting the lesion environment (Alexander and Popovich, 2009). In fact, activated microglia/macrophages can be detrimental by releasing proinflammatory cytokines, reactive oxygen species, and axonal outgrowth inhibitory keratane sulfate proteoglycans (Jones and Tuszynski, 2002; Bareyre and Schwab, 2003; Jones et al., 2005; David and Kroner, 2011). The increased proliferation of activated microglia/macrophages at the lesion site after SCI in $\mathrm{p} 53^{-/-}$mice could lead to an aberrant inflammatory response, exacerbated secondary degeneration, and the formation of a more aggressive inhibitory environment, contributing to a more pronounced motor impairment. The inhibition of glial proliferation by several pharmacological strategies including the use of cell cycle inhibitors ( $\mathrm{Wu}$ et al., 2011), such as Ara-C and Flavopiridol (Rhodes et al., 2003; Di Giovanni et al., 2005c; Byrnes et al., 2007), or the depletion of hematogenous macrophages by liposomeencapsulated clodronate (Popovich et al., 1999), has been shown to enhance axonal sprouting and functional recovery after both brain and spinal cord injury.

The role of p53 in regulating microglia/macrophage activity has not been extensively studied. A previous study suggested an increase in NF- $\kappa \mathrm{B}$-dependent transcription of several proinflammatory targets in $\mathrm{p} 53^{-1-}$ macrophages (Komarova et al., 2005); however, we found that the postinjury gene expression of IL-1 $\beta$, IL-6, and TNF $\alpha$ in the spinal cord was not affected by the absence of 553 (data not shown). Recent reports have indicated that, in a contusion spinal injury model, there is a predominance of classically activated or M1 macrophages at chronic stages after SCI and they contribute to the inhibition of axon regrowth (Kigerl et al., 2009) and to increased axon dieback (Horn et al., 2008), while M2 macrophages were shown to be neuroprotective in comparison. Interestingly, certain M2 subtypes have been associated with wound healing, matrix remodeling, and fibrosis (Wynn and Barron, 2010). Therefore, an aberrant M2 response could generate an environment that exacerbates scar formation after SCI. However, our data show that the absence of p53 does not alter M1/M2 polarization after SCI.

The glial and fibrotic scar formation is another crucial event in the response after SCI. Indeed, several components from the disrupted myelin and extracellular matrix components produced by reactive astrocytes, microglia, and fibrocytes show strong inhibitory properties on axonal outgrowth and regeneration, limiting the recovery of motor function after injury (Savio and Schwab, 1990; Schnell and Schwab, 1990; McKerracher et al., 1994; Bregman et al., 1995; Davies et al., 1999; Chen et al., 2000; Bradbury et al., 2002; GrandPré et al., 2002; Kottis et al., 2002; Sroga et al., 2003; Silver and Miller, 2004; Yiu and He, 2006; Hellal et al., 2011; Wang et al., 2011). In p53 ${ }^{-1-}$ injured cords, aberrant glial proliferation is accompanied by enhanced glial scar formation, as shown by GFAP- and fibronectin-positive scar tissue revealing a bigger reactive astrocyte area around the lesion site and an enlarged lesion core. Furthermore, mRNA expression analysis of the lesion site shows that genes associated with the fibrotic scar, including fibronectin, collagen $1 \alpha 2$, and collagen $4 \alpha 1$ (Stichel et al., 1999; Klapka et al., 2005; Moore and Goldberg, 2011) are differentially expressed in the absence of p53 following SCI. This observation gives us an insight of additional possible molecular components and mechanisms that contribute to the limited locomotor functional recovery we observed in $\mathrm{p} 53^{-1-}$ mice after SCI.
Together, our data show that p53 is involved in the regulation of axonal sprouting and plasticity, glial and fibrotic scar formation, and proliferation of microglia/macrophages affecting the recovery of motor function following SCI; in summary, we propose that, in response to a trauma, p53 plays a dual role at neuronal intrinsic and glial extrinsic levels. This suggests the modulation of $\mathrm{p} 53$ as a potential multilevel therapeutic strategy, which could be achieved by fine-tuning p53 at posttranslational or expression levels.

However, complementary studies with a compressive/contusive lesion model in p53 mutant mice would also be warranted to provide more convincing evidence of a translationally relevant role for $\mathrm{p} 53$.

\section{References}

Abbas T, Dutta A (2009) p21 in cancer: intricate networks and multiple activities. Nat Rev Cancer 9:400-414.

Alexander JK, Popovich PG (2009) Neuroinflammation in spinal cord injury: therapeutic targets for neuroprotection and regeneration. Prog Brain Res 175:125-137.

Aloyz RS, Bamji SX, Pozniak CD, Toma JG, Atwal J, Kaplan DR, Miller FD (1998) p53 is essential for developmental neuron death as regulated by the TrkA and p75 neurotrophin receptors. J Cell Biol 143:1691-1703.

Bareyre FM, Schwab ME (2003) Inflammation, degeneration and regeneration in the injured spinal cord: insights from DNA microarrays. Trends Neurosci 26:555-563.

Bareyre FM, Kerschensteiner M, Raineteau O, Mettenleiter TC, Weinmann O, Schwab ME (2004) The injured spinal cord spontaneously forms a new intraspinal circuit in adult rats. Nat Neurosci 7:269-277.

Basso DM, Fisher LC, Anderson AJ, Jakeman LB, McTigue DM, Popovich PG (2006) Basso Mouse Scale for locomotion detects differences in recovery after spinal cord injury in five common mouse strains. J Neurotrauma 23:635-659.

Behrmann DL, Bresnahan JC, Beattie MS, Shah BR (1992) Spinal cord injury produced by consistent mechanical displacement of the cord in rats: behavioral and histologic analysis. J Neurotrauma 9:197-217.

Bradbury EJ, Moon LD, Popat RJ, King VR, Bennett GS, Patel PN, Fawcett JW, McMahon SB (2002) Chondroitinase ABC promotes functional recovery after spinal cord injury. Nature 416:636-640.

Bregman BS, Kunkel-Bagden E, Schnell L, Dai HN, Gao D, Schwab ME (1995) Recovery from spinal cord injury mediated by antibodies to neurite growth inhibitors. Nature 378:498-501.

Byrnes KR, Garay J, Di Giovanni S, De Biase A, Knoblach SM, Hoffman EP, Movsesyan V, Faden AI (2006) Expression of two temporally distinct microglia-related gene clusters after spinal cord injury. Glia 53:420-433.

Byrnes KR, Stoica BA, Fricke S, Di Giovanni S, Faden AI (2007) Cell cycle activation contributes to post-mitotic cell death and secondary damage after spinal cord injury. Brain 130:2977-2992.

Cafferty WB, McGee AW, Strittmatter SM (2008) Axonal growth therapeutics: regeneration or sprouting or plasticity? Trends Neurosci 31:215-220.

Camand E, Morel MP, Faissner A, Sotelo C, Dusart I (2004) Long-term changes in the molecular composition of the glial scar and progressive increase of serotoninergic fibre sprouting after hemisection of the mouse spinal cord. Eur J Neurosci 20:1161-1176.

Carmel JB, Galante A, Soteropoulos P, Tolias P, Recce M, Young W, Hart RP (2001) Gene expression profiling of acute spinal cord injury reveals spreading inflammatory signals and neuron loss. Physiol Genomics 7:201-213.

Chen MS, Huber AB, van der Haar ME, Frank M, Schnell L, Spillmann AA, Christ F, Schwab ME (2000) Nogo-A is a myelin-associated neurite outgrowth inhibitor and an antigen for monoclonal antibody IN-1. Nature 403:434-439.

Culmsee C, Mattson MP (2005) p53 in neuronal apoptosis. Biochem Biophys Res Commun 331:761-777.

David S, Kroner A (2011) Repertoire of microglial and macrophage responses after spinal cord injury. Nat Rev Neurosci 12:388-399.

Davies SJ, Goucher DR, Doller C, Silver J (1999) Robust regeneration of adult sensory axons in degenerating white matter of the adult rat spinal cord. J Neurosci 19:5810-5822.

Di Giovanni S (2009) Molecular targets for axon regeneration: focus on the intrinsic pathways. Expert Opin Ther Targets 13:1387-1398. 
Di Giovanni S, Knoblach SM, Brandoli C, Aden SA, Hoffman EP, Faden AI (2003) Gene profiling in spinal cord injury shows role of cell cycle in neuronal death. Ann Neurol 53:454-468.

Di Giovanni S, Faden AI, Yakovlev A, Duke-Cohan JS, Finn T, Thouin M, Knoblach S, De Biase A, Bregman BS, Hoffman EP (2005a) Neuronal plasticity after spinal cord injury: identification of a gene cluster driving neurite outgrowth. FASEB J 19:153-154.

Di Giovanni S, De Biase A, Yakovlev A, Finn T, Beers J, Hoffman EP, Faden AI (2005b) In vivo and in vitro characterization of novel neuronal plasticity factors identified following spinal cord injury. J Biol Chem 280:2084-2091.

Di Giovanni S, Movsesyan V, Ahmed F, Cernak I, Schinelli S, Stoica B, Faden AI (2005c) Cell cycle inhibition provides neuroprotection and reduces glial proliferation and scar formation after traumatic brain injury. Proc Natl Acad Sci U S A 102:8333-8338.

Di Giovanni S, Knights CD, Rao M, Yakovlev A, Beers J, Catania J, Avantaggiati ML, Faden AI (2006) The tumor suppressor protein p53 is required for neurite outgrowth and axon regeneration. EMBO J 25:4084-4096.

el-Deiry WS, Tokino T, Velculescu VE, Levy DB, Parsons R, Trent JM, Lin D, Mercer WE, Kinzler KW, Vogelstein B (1993) WAF1, a potential mediator of p53 tumor suppression. Cell 75:817-825.

Faden AI, Gannon A, Basbaum AI (1988) Use of serotonin immunocytochemistry as a marker of injury severity after experimental spinal trauma in rats. Brain Res 450:94-100.

Floriddia E, Nguyen T, Di Giovanni S (2011) Chromatin immunoprecipitation from dorsal root ganglia tissue following axonal injury. J Vis Exp pii:2803.

Giger RJ, Venkatesh K, Chivatakarn O, Raiker SJ, Robak L, Hofer T, Lee H, Rader C (2008) Mechanisms of CNS myelin inhibition: evidence for distinct and neuronal cell type specific receptor systems. Restor Neurol Neurosci 26:97-115.

GrandPré T, Li S, Strittmatter SM (2002) Nogo-66 receptor antagonist peptide promotes axonal regeneration. Nature 417:547-551.

Hamers FP, Lankhorst AJ, van Laar TJ, Veldhuis WB, Gispen WH (2001) Automated quantitative gait analysis during overground locomotion in the rat: its application to spinal cord contusion and transection injuries. J Neurotrauma 18:187-201.

Hargreaves K, Dubner R, Brown F, Flores C, Joris J (1988) A new and sensitive method for measuring thermal nociception in cutaneous hyperalgesia. Pain 32:77-88.

Hellal F, Hurtado A, Ruschel J, Flynn KC, Laskowski CJ, Umlauf M, Kapitein LC, Strikis D, Lemmon V, Bixby J, Hoogenraad CC, Bradke F (2011) Microtubule stabilization reduces scarring and causes axon regeneration after spinal cord injury. Science 331:928-931.

Hill RL, Zhang YP, Burke DA, Devries WH, Zhang Y, Magnuson DS, Whittemore SR, Shields CB (2009) Anatomical and functional outcomes following a precise, graded, dorsal laceration spinal cord injury in C57BL/6 mice. J Neurotrauma 26:1-15.

Horn KP, Busch SA, Hawthorne AL, van Rooijen N, Silver J (2008) Another barrier to regeneration in the CNS: activated macrophages induce extensive retraction of dystrophic axons through direct physical interactions. J Neurosci 28:9330-9341.

Jacks T, Remington L, Williams BO, Schmitt EM, Halachmi S, Bronson RT, Weinberg RA (1994) Tumor spectrum analysis in p53-mutant mice. Curr Biol 4:1-7.

Johnson DG, Walker CL (1999) Cyclins and cell cycle checkpoints. Annu Rev Pharmacol Toxicol 39:295-312.

Jones LL, Tuszynski MH (2002) Spinal cord injury elicits expression of keratan sulfate proteoglycans by macrophages, reactive microglia, and oligodendrocyte progenitors. J Neurosci 22:4611-4624.

Jones TB, McDaniel EE, Popovich PG (2005) Inflammatory-mediated injury and repair in the traumatically injured spinal cord. Curr Pharm Des 11:1223-1236.

Kigerl KA, Gensel JC, Ankeny DP, Alexander JK, Donnelly DJ, Popovich PG (2009) Identification of two distinct macrophage subsets with divergent effects causing either neurotoxicity or regeneration in the injured mouse spinal cord. J Neurosci 29:13435-13444.

Klapka N, Hermanns S, Straten G, Masanneck C, Duis S, Hamers FP, Müller D, Zuschratter W, Müller HW (2005) Suppression of fibrous scarring in spinal cord injury of rat promotes long-distance regeneration of corticospinal tract axons, rescue of primary motoneurons in somatosensory cortex and significant functional recovery. Eur J Neurosci 22:3047-3058.
Knoblach SM, Huang X, VanGelderen J, Calva-Cerqueira D, Faden AI (2005) Selective caspase activation may contribute to neurological dysfunction after experimental spinal cord trauma. J Neurosci Res 80:369-380.

Komarova EA, Krivokrysenko V, Wang K, Neznanov N, Chernov MV, Komarov PG, Brennan ML, Golovkina TV, Rokhlin OW, Kuprash DV, Nedospasov SA, Hazen SL, Feinstein E, Gudkov AV (2005) p53 is a suppressor of inflammatory response in mice. FASEB J 19:1030-1032.

Kottis V, Thibault P, Mikol D, Xiao ZC, Zhang R, Dergham P, Braun PE (2002) Oligodendrocyte-myelin glycoprotein (OMgp) is an inhibitor of neurite outgrowth. J Neurochem 82:1566-1569.

Liebermann DA, Hoffman B, Vesely D (2007) p53 induced growth arrest versus apoptosis and its modulation by survival cytokines. Cell Cycle 6:166-170.

Liu K, Tedeschi A, Park KK, He Z (2011) Neuronal intrinsic mechanisms of axon regeneration. Annu Rev Neurosci 34:131-152.

Loane DJ, Byrnes KR (2010) Role of microglia in neurotrauma. Neurotherapeutics 7:366-377.

Ma M, Basso DM, Walters P, Stokes BT, Jakeman LB (2001) Behavioral and histological outcomes following graded spinal cord contusion injury in the C57BL/6 mouse. Exp Neurol 169:239-254.

Maier IC, Ichiyama RM, Courtine G, Schnell L, Lavrov I, Edgerton VR, Schwab ME (2009) Differential effects of anti-Nogo-A antibody treatment and treadmill training in rats with incomplete spinal cord injury. Brain 132:1426-1440.

McKerracher L, David S, Jackson DL, Kottis V, Dunn RJ, Braun PE (1994) Identification of myelin-associated glycoprotein as a major myelinderived inhibitor of neurite growth. Neuron 13:805-811.

Missero C, Di Cunto F, Kiyokawa H, Koff A, Dotto GP (1996) The absence of p21Cip1/WAF1 alters keratinocyte growth and differentiation and promotes ras-tumor progression. Genes Dev 10:3065-3075.

Mogil JS, Wilson SG, Bon K, Lee SE, Chung K, Raber P, Pieper JO, Hain HS, Belknap JK, Hubert L, Elmer GI, Chung JM, Devor M (1999) Heritability of nociception I: responses of 11 inbred mouse strains on 12 measures of nociception. Pain 80:67-82.

Moore DL, Goldberg JL (2011) Multiple transcription factor families regulate axon growth and regeneration. Dev Neurobiol 71:1186-1211.

Müllner A, Gonzenbach RR, Weinmann O, Schnell L, Liebscher T, Schwab ME (2008) Lamina-specific restoration of serotonergic projections after Nogo-A antibody treatment of spinal cord injury in rats. Eur J Neurosci 27:326-333.

Oatway MA, Chen Y, Bruce JC, Dekaban GA, Weaver LC (2005) AntiCD11d integrin antibody treatment restores normal serotonergic projections to the dorsal, intermediate, and ventral horns of the injured spinal cord. J Neurosci 25:637-647.

Oren M (2003) Decision making by p53: life, death and cancer. Cell Death Differ 10:431-442.

Park JB, Yiu G, Kaneko S, Wang J, Chang J, He XL, Garcia KC, He Z (2005) A TNF receptor family member, TROY, is a coreceptor with Nogo receptor in mediating the inhibitory activity of myelin inhibitors. Neuron 45: 345-351.

Pietenpol JA, Stewart ZA (2002) Cell cycle checkpoint signaling: cell cycle arrest versus apoptosis. Toxicology 181-182:475-481.

Popovich PG, Guan Z, Wei P, Huitinga I, van Rooijen N, Stokes BT (1999) Depletion of hematogenous macrophages promotes partial hindlimb recovery and neuroanatomical repair after experimental spinal cord injury. Exp Neurol 158:351-365.

Qin Q, Baudry M, Liao G, Noniyev A, Galeano J, Bi X (2009) A novel function for p53: regulation of growth cone motility through interaction with Rho kinase. J Neurosci 29:5183-5192.

Qin Q, Liao G, Baudry M, Bi X (2010) Role of calpain-mediated p53 truncation in semaphorin 3A-induced axonal growth regulation. Proc Natl Acad Sci U S A 107:13883-13887.

Raineteau O, Schwab ME (2001) Plasticity of motor systems after incomplete spinal cord injury. Nat Rev Neurosci 2:263-273.

Raineteau O, Fouad K, Bareyre FM, Schwab ME (2002) Reorganization of descending motor tracts in the rat spinal cord. Eur J Neurosci 16:17611771.

Rhodes KE, Moon LD, Fawcett JW (2003) Inhibiting cell proliferation during formation of the glial scar: effects on axon regeneration in the CNS. Neuroscience 120:41-56.

Saito N, Yamamoto T, Watanabe T, Abe Y, Kumagai T (2000) Implications 
of p53 protein expression in experimental spinal cord injury. J Neurotrauma 17:173-182.

Sakaguchi K, Herrera JE, Saito S, Miki T, Bustin M, Vassilev A, Anderson CW, Appella E (1998) DNA damage activates p53 through a phosphorylationacetylation cascade. Genes Dev 12:2831-2841.

Saruhashi Y, Young W, Perkins R (1996) The recovery of 5-HT immunoreactivity in lumbosacral spinal cord and locomotor function after thoracic hemisection. Exp Neurol 139:203-213.

Saura J, Tusell JM, Serratosa J (2003) High-yield isolation of murine microglia by mild trypsinization. Glia 44:183-189.

Savio T, Schwab ME (1990) Lesioned corticospinal tract axons regenerate in myelin-free rat spinal cord. Proc Natl Acad Sci U S A 87:4130-4133.

Schnell L, Schwab ME (1990) Axonal regeneration in the rat spinal cord produced by an antibody against myelin-associated neurite growth inhibitors. Nature 343:269-272.

Schnell L, Schwab ME (1993) Sprouting and regeneration of lesioned corticospinal tract fibres in the adult rat spinal cord. Eur J Neurosci 5:1156-1171.

Shen Y, Tenney AP, Busch SA, Horn KP, Cuascut FX, Liu K, He Z, Silver J, Flanagan JG (2009) PTPsigma is a receptor for chondroitin sulfate proteoglycan, an inhibitor of neural regeneration. Science 326:592-596.

Silver J, Miller JH (2004) Regeneration beyond the glial scar. Nat Rev Neurosci 5:146-156.

Simonen M, Pedersen V, Weinmann O, Schnell L, Buss A, Ledermann B, Christ F, Sansig G, van der Putten H, Schwab ME (2003) Systemic deletion of the myelin-associated outgrowth inhibitor Nogo-A improves regenerative and plastic responses after spinal cord injury. Neuron 38:201-211.

Sroga JM, Jones TB, Kigerl KA, McGaughy VM, Popovich PG (2003) Rats and mice exhibit distinct inflammatory reactions after spinal cord injury. J Comp Neurol 462:223-240.

Steward O, Zheng B, Tessier-Lavigne M (2003) False resurrections: distin- guishing regenerated from spared axons in the injured central nervous system. J Comp Neurol 459:1-8.

Steward O, Zheng B, Tessier-Lavigne M, Hofstadter M, Sharp K, Yee KM (2008) Regenerative growth of corticospinal tract axons via the ventral column after spinal cord injury in mice. J Neurosci 28:6836-6847.

Stichel CC, Hermanns S, Luhmann HJ, Lausberg F, Niermann H, D’Urso D, Servos G, Hartwig HG, Müller HW (1999) Inhibition of collagen IV deposition promotes regeneration of injured CNS axons. Eur J Neurosci 11:632-646.

Tedeschi A, Nguyen T, Puttagunta R, Gaub P, Di Giovanni S (2009a) A p53-CBP/p300 transcription module is required for GAP-43 expression, axon outgrowth, and regeneration. Cell Death Differ 16:543-554.

Tedeschi A, Nguyen T, Steele SU, Feil S, Naumann U, Feil R, Di Giovanni S (2009b) The tumor suppressor p53 transcriptionally regulates cGKI expression during neuronal maturation and is required for cGMPdependent growth cone collapse. J Neurosci 29:15155-15160.

Tian DS, Yu ZY, Xie MJ, Bu BT, Witte OW, Wang W (2006) Suppression of astroglial scar formation and enhanced axonal regeneration associated with functional recovery in a spinal cord injury rat model by the cell cycle inhibitor olomoucine. J Neurosci Res 84:1053-1063.

Tian DS, Xie MJ, Yu ZY, Zhang Q, Wang YH, Chen B, Chen C, Wang W (2007) Cell cycle inhibition attenuates microglia induced inflammatory response and alleviates neuronal cell death after spinal cord injury in rats. Brain Res 1135:177-185.

Wang D, Ichiyama RM, Zhao R, Andrews MR, Fawcett JW (2011) Chondroitinase combined with rehabilitation promotes recovery of forelimb function in rats with chronic spinal cord injury. J Neurosci 31:9332-9344.

Wu J, Stoica BA, Faden AI (2011) Cell cycle activation and spinal cord injury. Neurotherapeutics 8:221-228.

Wynn TA, Barron L (2010) Macrophages: master regulators of inflammation and fibrosis. Semin Liver Dis 30:245-257.

Yiu G, He Z (2006) Glial inhibition of CNS axon regeneration. Nat Rev Neurosci 7:617-627. 